\title{
THE VISUAL DETECTION OF DRIVING WHILE INTDXICATED \\ FIELD TEST OF VISUAL CUES AND DETECTION METHODS
}

Douglas H. Harris

Robert A. Dick

Steven M. Cosey

Christopher I. Jarose

Anacapa Sciences, Inc.

P.O. Drawer 0

Santa Barbara, Calfornia 93102

\section{Contract No. DOT-HS-7-01538 \\ Contract Amt. \$271,834}

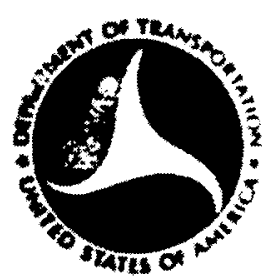

\section{APRIL 1980 \\ FNAL REPORT}

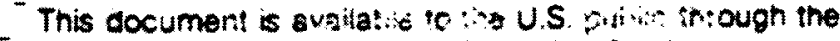

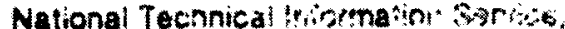

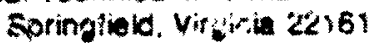

Prepared for U.S. DEPARTMENT OF TRANSPQRTATION National Highway Traffic Safety Akssinistration Washington, D.C. 20593 
This docwont is disseninated under the oponsorahip of the Dapartant of Transportation in the interest of Information exchange. The Onsted gtates covernment ascumes no 11 bility for 1ts contants or ase thereot. 


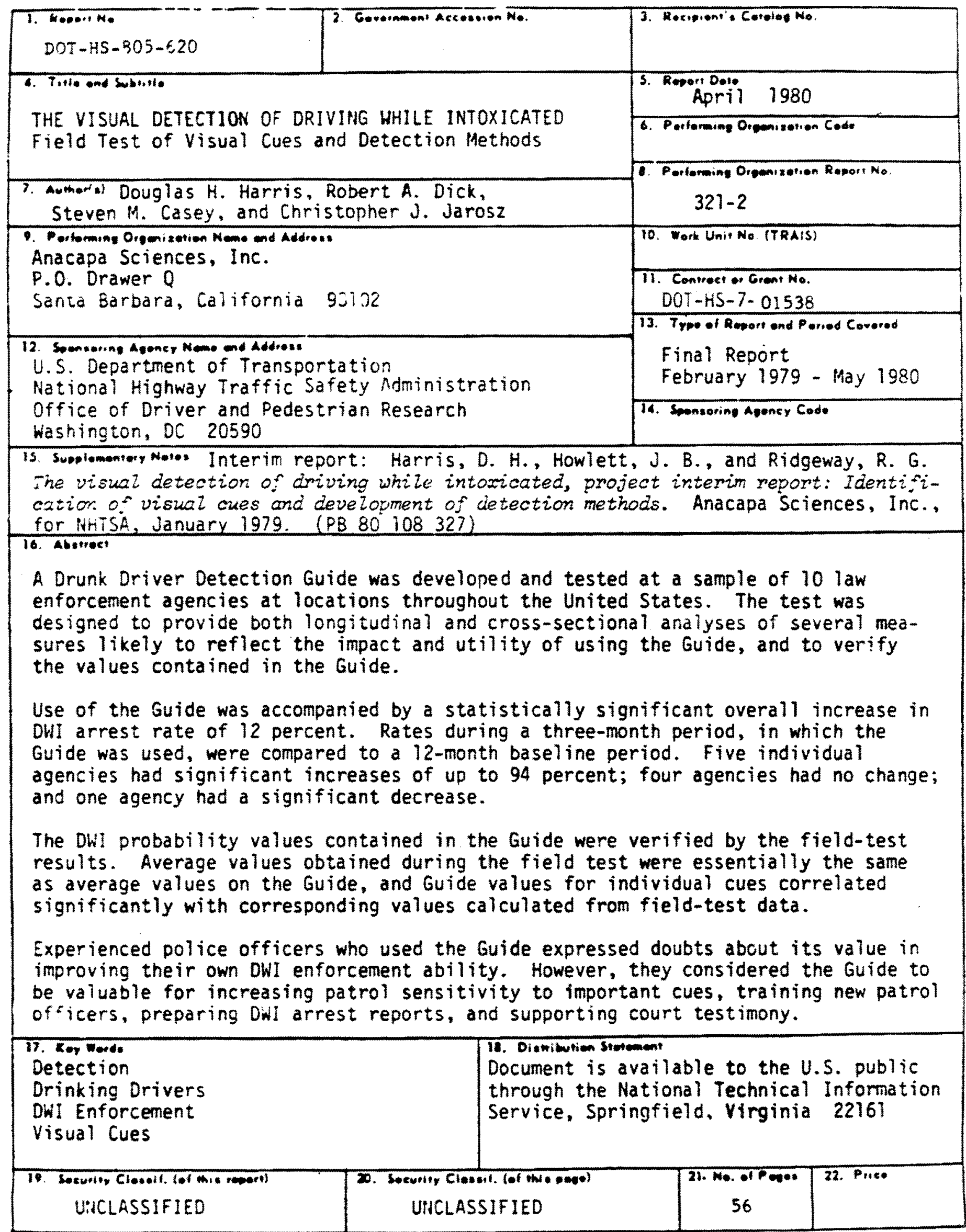




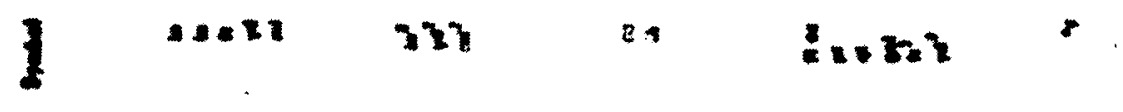

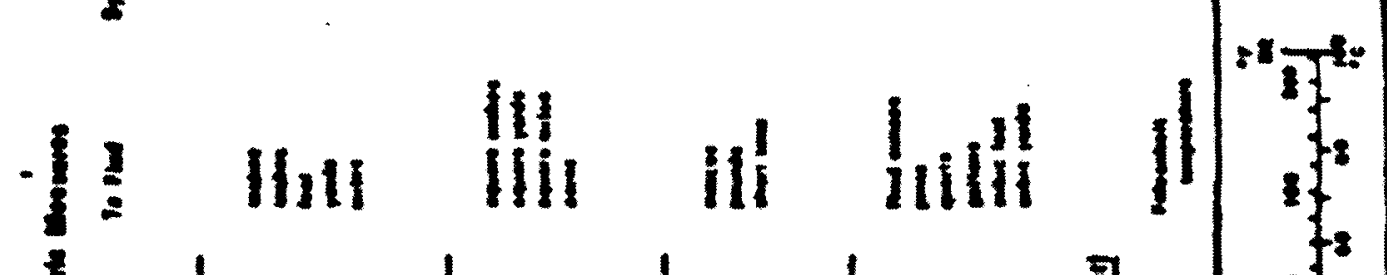

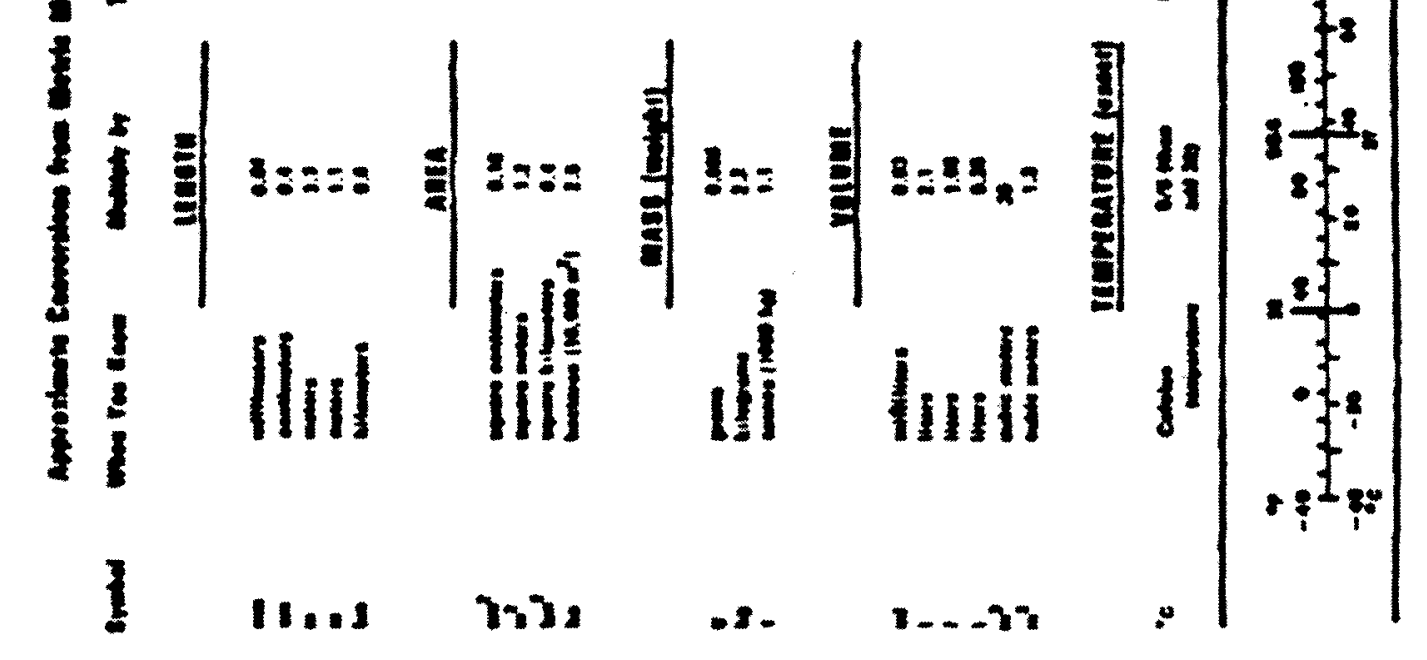

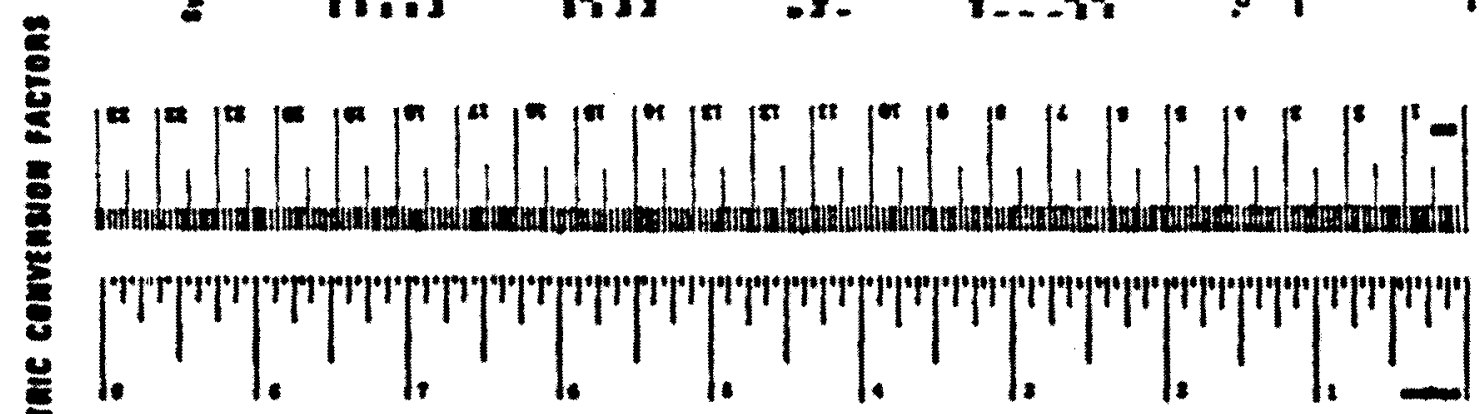

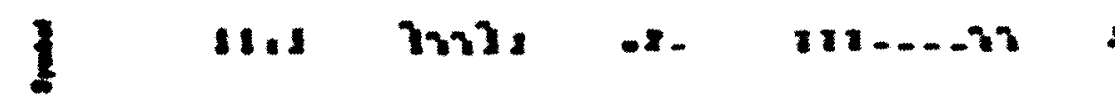

$$
\begin{aligned}
& \text { I! }
\end{aligned}
$$

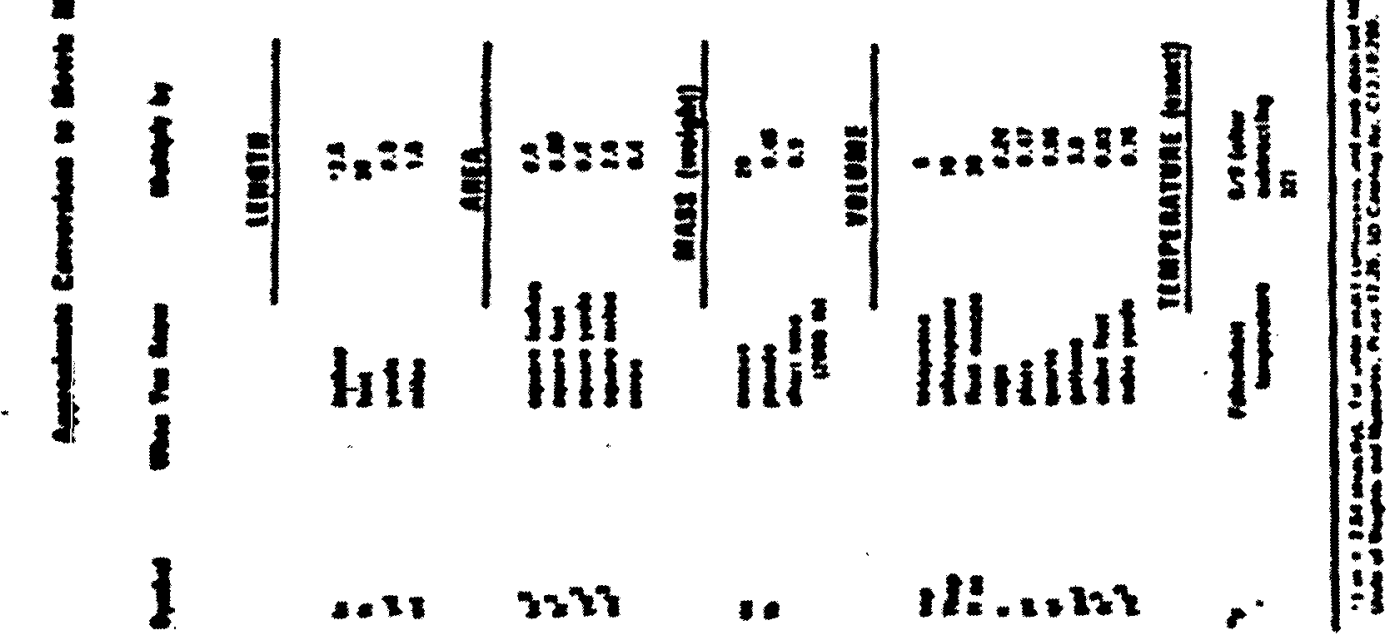




\section{PREFACE}

This is the second of two reports prepared under Contract DOT-HS-701538 on the visual detection of driving while intoxicated. The initial report described the identification of visual cues and development of detection methods that led to a Drunk Driver Detection Guide. This report describes the Guide, and the field test conducted to evaluate and verify the Guide.

The study involved the participation of 10 different police agencies; without the cooperation and support of these agencies the work would not have been possible. We are grateful for the exceptional contributions to the project of the administrative and patrol personnel of these agencies. The agencies, along with our principal point of contact, are listed below in alphabetical order.

Albuquerque (New Mexico) Police Department: Lieutenant John Nelson Englewood (Colorado) Police Department: Captain Allan Stanley

Eugene (Oregon) Police Department: Sergeant Robert Laws

Evansville (Indiana) Police Department: Captain James Kleeman

Monroe County (New York) Sheriff's Office: Captain Robert Wilsey

Pulaski County (Arkansas) Sheriff's Office: Lieutenant Jim Kemmeling Santa Ana (California) Police Department: Lieutenant Jack Nelson

Tacoma (Washington) Police Department: Captain Phil Sessions

Topeka (Kansas) Police Department: Major Dan Mallory

Vanderburgh County (Indiana) Sheriff's office: Sergeant Jim Fravel

The Contract Technical Manager of this phase of the project was Mr. william C. Wheeler, Jr.; are appreciative of the assistance and support he provided.

Data processing was designed and conducted by Mr. Curtiss Mosso, computer Center, University of California at Santa Barbara, using the Statistical Analys is System (SAS). 


\section{LIST OF TABLES}

Table

Page

1 DWI Arrests per 100 Person-Hours of Patrol

During Baseline and Test Periods by Agency. . . . . . 23

2 DWI Arrests per 100 Person-Hours of Patrol

During Baseline and Test Periods by Patrol Type... . 25

3 Mean Number of Cues Reported per DWI Arrest

During Baseline and Test Periods by Agency. . . . . 25

4 Frequency Distributions of Detection Cues

Recorded on DWI Arrest Reports During Baseline

and Test Periods................ 27

5 Mean BAC of Persons Arrested During Baseline

and Test Periods by Agency. . . . . . . . . . . 28

6 Comparison of Cue Probability Values of Detection

Guide with Values Obtained from Field-Test

Data for $P(B A C \geq .10) \ldots . \ldots 30$

7 Comparison of Cue Probability Values of Detection

Guide with Values obtained from Field-Test

Data for $\mathrm{P}(\mathrm{BAC} \geq .05) \ldots \ldots 1$

$8 \quad$ Cue Discriminability Values Computed from 4662

Detections Made During Detection and Field

Studies: $P(B A C \geq .10) . \ldots 35$

9 Cue Discriminability Values Computed from 4662

Detections Made During Detection and Field

Studies: $P(B A C \geq .05) \ldots . . . . . . . .36$

10 Sumary of the Content Analysis of Group Discussions

Conducted at Each Participating Agency Regarding

Guide Utility................... 37 


\section{TABLE OF CONTENTS}

Page

TECHNICAL SUMMARY......................... 1

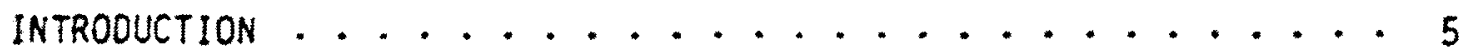

Background .................... 6

Field-Test Objectives......................... 10

METHOD . . . . . . . . . . . . . . . . . . . 12

Field-Test Design................. 12

Participating Agencies .............. 15

Field-Test Procedures............... 15

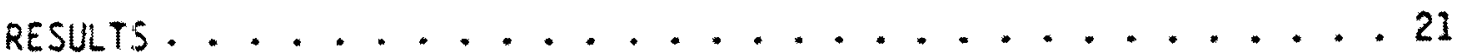

Impact on DWI Arrest Rates . . . . . . . . . . . 21

Changes in DWI Detection Practices........... 24

Ver ification of the Guide................ 26

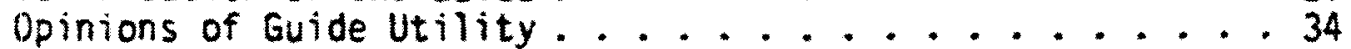

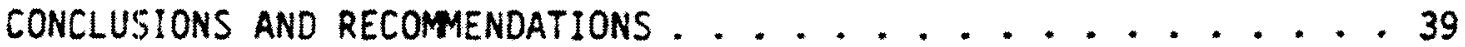

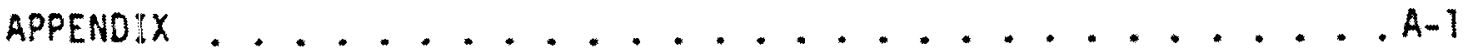

\section{LIST OF FIGURES}

Figure Page

1 FIELD STUDY EXPERIMENTAL DESIGN ............ 14

2 FORM FOR RECORDING DETECTION EVENTS. ........ 17

3 QUARTERLY DWI ARREST RATES FOR ALL 10 PARTICIPATING AGENCIES DURING BASELINE AND TEST PERIODS....... 22

4 COMPARISON OF AVERAGE CUE PROBABILITY VALUES OF THE GUIDE WITH THOSE CALCULATED FROM THE FIELD TEST $\ldots \ldots 29$

5 DISPOSITION OF 4019 APPREHENSIONS RECORDED ON DRUNK DRIVER DETECTION GUIDE AND RECORD FORMS DURING THREE-MONTH TEST PERIOO ........... 33

6 MODIFIED DRUNK DRIVER DETECTION GUIDE ........ 41 


\section{TECHNICAL SUMMARY}

On-the-road detection of driving while intoxicated (DWI) involves the observation and interpretation of visual cues by police patrol officers. The effectiveness of DWI detection depends not only on the frequency with which patrol officers see and recognize cues indicative of DWI, but on the extent to which observed cues discriminate between DWI and driving while sober (DWS). This research project was conducted to answer the following questions: What visual cues occur frequently enough to be useful for OWI detection? To what extent do different cues discriminate between DW: and DWS? How can information on cue occurrence and discriminability be used best for on-the-road detection of DWI?

In the first phase of the project, reported earlier, the literature was reviewed, DWI detection experts were interviewed, a large sample of arrest reports was analyzed, and an on-the-road study of DWI detection was conducted to obtain data on the relative discriminability and frequency of occurrence of visual detection cues. The end product of the first phase was a set of conclusions about DWI detection, and a prototype DWI detection guide designed to facilitate application of the research findings to onthe-road detection of DWI.

In the second phase of the project, reported here, a DWI Detection Guide and an explanatory booklet were developed and tested. The Guide was a small card of white plastic printed with blue.

The field test of the Guide was conducted with a sample of 10 law enforcement agencies at locations throughout the United States. The test was designed to provide both longitudinal and cross-sectional analyses of several measures likely to reflect the impact and utility of using the Guide, and to verify the values contained in the Guide. 
Use of the Guide was accompanied by a statistically significant overall increase in DWI arrest rate of 12 percent. Rates during a 3-month period, in which the Guide was used, were compared to a 12-month baseline period. Five individual agencies had significant increases of up to 94 percent; four agencies had no change; and one agency had a significant decrease.

Although there were no statistically significant changes in detection practices reflected by greater use of the more discriminating cues or by arrests of drivers with lower BAC levels, trends were in those directions.

The DWI probability values contained in the Guide were verified by the field-test results. Average values obtained during the field test were essentially the same as average values on the Guide, and Guide values for individual cues correlated significantly with corresponding values calculated from field-test data.

Experienced police officers who used the Guide expressed doubts about its value in improving their own DWI enforcenent ability. However, they considered the Guide to be valuable for increasing patrol sensitivity to important cues, training new patrol officers, preparing DWI arrest reports, and supporting court testimony.

Field-test results led to a couple of minor modifications in the Guide and the explanatory book let. DWI detection probabilities were based on combined data from the early detection study and from the field test, thus providing a data base of 4662 detection events. Several other minor modifications were made to further simplify and clarify the Guide. The resulting DWI Detection Guide is shown below. 


\section{DWI DETECTION GUIDE}

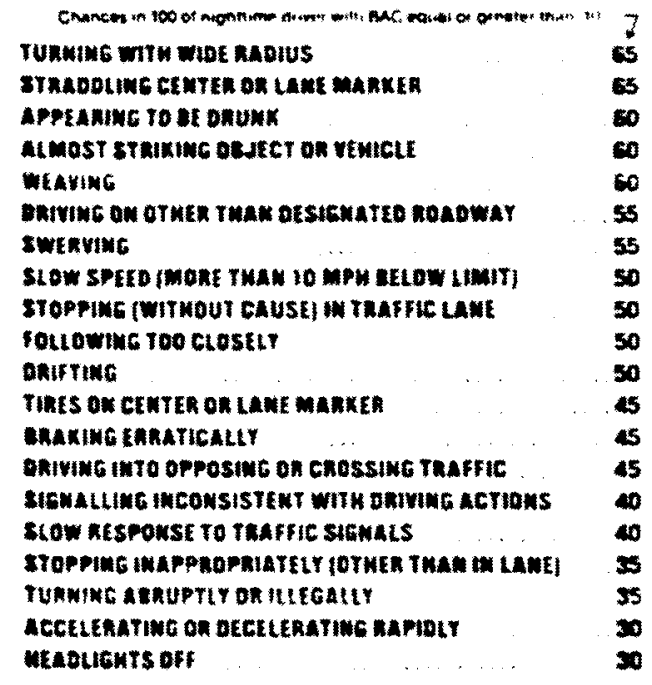

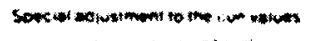

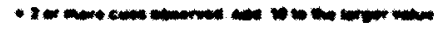

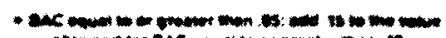

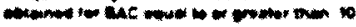

A short $16-\mathrm{mm}$ sound film in color was produced to describe the detection cues and introduce the Guide. 


\section{INTRODUCTION}

On-the-road detection of driving while intoxicated (DWI) involves the observation and interpretation of visual cues by police patrol officers. The effectiveness of DWI detection depends not only on the frequency with which patrol officers see and recognize cues indicative of DWI, but on the extent to which observed cues discriminate between DWI and driving while sober (DWS). This research project was conducted to answer the following three questions:

- What visual cues occur frequentiy enough to be useful for DWI detection?

- To what extent do different cues discriminate between DWI and DWS?

- How can findings on cue occurrence and discriminability best be incorporated into practical procedures for on-the-road detection of DWI?

The initial phase of the project addressed and provided preliminary answers to these three questions by identifying useful visual cues and developing DWI detection methods. The primary products of the initial phase were an interim report ${ }^{1}$ and a proposed DWI detection guide. In this final phase of the project, a Drunk Driver Detection Guide was developed, and a field test was conducted to evaluate and verify the Guide. Prior to describing the objectives, methodology, and results of the field test, a summary of the interim report is provided as background.

Harris, D. H., Howlett, J. B., and Ridgeway, R. G. The visual detection of driving wile intoxicated, project inter im report: Identification of visual cues and development of detection methods. Anacapa Sciences, Inc.. for Department of Transportation, National Highway Traffic Safety Administration, January 1979. (NHTSA Technical Reference No. HS 805051 ; NTIS No. PB 80108327 ). 


\section{BACKEROUND}

Only a very small proportion of persons DWI are arrested for this offense-monly about one in 2000. Reasons for a low arrest rate might include limitations on enforcement resources, lack of enforcement motivation, inability to detect DWI, and others. However, previous research has also shown that even when persons DWI have been observed by police officers who were highly motivated to arrest for DWI, the arrest rate was relatively low.

As determined from roadside breathtesting surveys conducted throughout the United States, about six percent of drivers at night have a blood alcohol concentration (BAC) equal to or greater than .10 . About 15 percent have a $B A C$ equal to or greater than .05 . Thus, if DWI were defined at the $B A C \geq .10$ level, the probability of detecting OWI from a random stop would be .06 ; at $B A C \geq .05$, the probability would be .15 . Visual cues that are capable of discriminating between DWI and DWS can serve to increase detection probabilities above these chance levels. Thus, the key to enhanced on-the-road detection of DWI is determination of the relative discriminability of visual cues that are likely to be observed in association with DWI.

\section{Previous Research}

Kany studies have investigated the effect of alcohol on driving behavior. They have employed laboratory apparatus, oriving simulators, and instrumented vehicles in the field. However, results have been only indirectly relevant to the objectives of the present project. Although substantial evidence has been developed to indicate that alcohol-induced oriver impairment is exhibited mainly in four driving functions--steering control, velocity control, time-sharing of attention, and information processing--the findings have not been specific enough to permit the identification and assessment of visual cues for on-the-road detection. 
Lists of cues have been developed through interviews with police officers experienced in DWI detection, including a listing developed from a survey conducted in the present study. The resulting listings have been both comprehensive and logically organized; however, they have been of only limited use for DWI detection. Without information about the relative frequencies of cue occurrence and relative cue discriminability, there can be no basis for defining useful visual cues or developing practical guidelines for DWI detection.

Analys is of DUI Arrests

An analysis was completed of a sample of 1288 DWI arrest reports obtained from nine different police agencies throughout the United States for arrests made during the previous year. A total of 3658 visual detection cues was reported in the sample, an average of about three cues per arrest. Frequency distributions prepared from the data, combined with the results of previous research and cue listings obtained from experienced patrol officers, provided a preliminary listing of 129 visual cues potentially useful for DWI detection.

\section{On-the-Road Detection Study}

An on-the-road study of DWI detection was conducted to determine the relative discriminability and frequency of occurrence of visual detection cues, under conditions typically encountered by police officers. Trained observers accompanied police officers on patrol and recorded instances of driving behavior and vehicle actions that deviated from normal. In each instance, the police officer stopped the vehicle and measured the BAC of the driver with a portable breath tester. In addition to cue descriptions and $B A C$ level, the observer recorded the circunstances and conditions under which the stop was made, and driver characteristics. Since the data collection effort required conducting pre-arrest breath tests of drivers, the study was conducted in two states, Indiana and North Carolina, that permitted, by statute, pre-arrest breath testing. 
A total of 643 DWl detection events was observed and recorded. The sample was comparable to the national sample of 1288 DWI arrests in terms of time of day of stops, location (urban vs rural) of the stops, and sex of the oriver. As expected, the main way in which the detection study sample differed from the arrest report sample was in the distribution of the $B A C$ levels of the drivers. In the detection study, 39 percent of the drivers had a $B A C \geq .05 ; 23$ percent had a $B A C$ in the range from .05 to 0.10 ; and 38 percent had a $B A C \geq .10$. By contrast, 96 percent of the sample of DWI arrests reported drivers with $B A C \geq .10$.

Analyses of the 1681 cue occurrences recorded during the 643 detection events included: computation of cue frequencies, calculation of cue discrimability values, study of cue co-occurrence, assessment of cue order of appearance, and correlational analyses to determine the impact on cue occurrence of alternative detection strategies, characteristics, and conditions. As part of the analytical effort, cues were recombined and redefined, ultimately, into a set of 23 visual cues that accounted for 93 percent of the cue occurrences in the detection study. The following conclusions were developed fram the results of the study:

- Although the potential number of visual detection cues is very large, most detection events can be accounted for by a relatively small number of cues.

- Typically, detection cue is observed with one or more other cues; however, there are few subsets of specific cues that occur frequently together.

- There are large differences anong visual detection cues in the frequency with which they occur with DWI, and in their ability to discriminate between DWI and DWS.

- In general, the conditions (lighting, time of day, distance, location, vehicle condition, type of roadway, age or sex of driver) under which cues are observed have relatively little influence on cue occurrence. 
- Patrol strategy (general patrol vs. patrol with DWI emphasis) greatly affects the relative frequencies with which cues are observed.

\section{DNI Detection Guide}

A preliminary DWI detection guide was developed to facilitate the application of research findings to on-the-road detection of DWI by police patrol officers. The extent of competing demands placed upon patrol officers--the variety of situations likely to be encountered, the stringent demands on available time, the need for rapid response, and the large amount of other law enforcement information that must also be learned and retained--suggested that the findings of this study be presented for use simply and directly. Therefore, the guide was developed to transform the research findings into a practical aid for DWI detection. Because the empirical results were not necessarily simple or free of subtlety, extrapolation and judgment were exercised during this process. Guide development was governed by the following criteria:

- Account for the largest number of detection events with the smallest number of detection cues.

- Enhance the discriminability of available detection cues.

- Employ a probabilistic output.

- Accomodate multiple cue occurrences.

- Accormodate alternative enforcement statutes and policies.

- Emphasize simplicity, practicality, and ease of use.

A DWI detection guide was developed conceptually in this initial phase of the project. The concept was refined and transformed during the first part of the field-test into the Drunk Driver Detection Guide shown in the Appendix. 


\section{FIELD-TEST OBJECTIVES}

The purpose of the field test was to evaluate and verify the Drunk Driver Detection Guide. There were four different facets of the field test, as reflected in the following four specific objectives:

1. Determine the potential impact of the Guide on DWI arrest rates. The ultimate criterion for evaluating the Guide was the extent to which it enhanced DWI enforcement, as reflected by increased. DWI arrest rates. However, although detection accuracy is likely to influence enforcement rate, it is surely not the only factor that does. Other factors also influence the decision of the patrol officer, first, to apprehend or not apprehend a driver and, second, to arrest or release the apprehended driver. As a consequence, the ultimate criterion of enhanced DWI enforcement, as measured by DWI arrest rate, is likely to be contaminated for purposes of evaluating the Guide. On the other hand, if use of the Guide cannot be shown, under present circumstances, to have some positive impact on the rate of DWI arrests, its ultimate contribution to DWI enforcement will probably be minimal.

\section{Determine the extent to wich DWI detection practices are} changed through use of the Guide. Is the form of the Guide and the training provided for its use adequate to modify OWI detection practices? Are the more discriminating cues reported more frequently as a result of using the Guide? Are average BAC levels of arrested drivers DWI lower as a result of detecting and arresting more drivers near the .10 threshold?

3. Verify the Guide. Development of the Guide was based mainly on data collected during 643 DWI detection events. Prior to any widespread use of the Guide, cue frequency distributions and discriminability values require verification through additional data obtained from additional DWI detection events.

4. Evaluate the Guide as a practical, useful detection aid. Is the Guide too awkward to be of practical benefit? Is the Guide too 
simple to provide the information needed? Does the Guide provide too little face validity to instill confidence in the user? These and other questions were addressed in the field study to obtain information that might be useful to modify the Guide.

The field test was limited to an assessment of the visual detection of DWI. Therefore, detections were restricted to those made visually by patrol officers while the driver suspected of DWI was in the car. DWI arrests made as a consequence of an accident or by an officer dispatched in response to a request were eliminated. 


\section{METHOD}

The field test of the Guide was conducted with a sample of 10 law enforcement agencies at locations throughout the United States. The test was designed to provide both longitudinal and cross-sectional analyses of several measures likely to reflect the impact and utility of using the Drunk Driver Detection Guide, and to verify the detection probabilities contained in the Guide.

\section{FIELD-TEST DESIGN}

The design was a compromise between what would be required for the most definitive possible evaluation and what was practically feasible in terms of police cooperation and available resources. Under the pressures that existed throughout the country for increased police efficiencies and for more police sensitivity to individual privacy, field-test procedures could be neither burdensome nor potentially embarrassing to individual police agencies. Consequently, it was within these constraints that the field test was designed. Although less than optimal from a theoretical perspective, the design did provide an adequate basis for evaluation of the Guide while placing a minimum burden on the part of participating police agencies.

\section{Experimental Design}

A within-subjects type of experimental design was employed with 10 participating police agencies. Measures related to DWI enforcement effectiveness were obtained from each agency during a 12-month baseline period and during a three-month test period in which the Guide was used. Three measures were obtained during both baseline and test periods: DWI arrest rate, frequencies of reported detection cues, and BAC levels of persons arrested. During the three-month test period, two additional measures were obtained: ratio of drivers DWI to drivers apprehended for each cue or cue combination, and opinions and suggestions of participating police officers regarding use of the Guide. The experimental design is illustrated in the diagram of Figure 1. 


\section{Field-Test measures}

The five different measures obtained during the field test related directly to one or more of the field-test objectives. The measures are described in the following paragraphs; the data-collection and analysis procedures required by each measure are discussed later.

DWI arrest rate. This mezsure was defined as the number of OWI arrests made per unit of patrol effort. Rates were calculated monthly for each agency, in terms of number of DWI arrests per 100 person-hours of patrol activity, during both baseline and test periods.

Frequencies of reported detection cues. Frequency distributions of cues reported on DWI arrest reports were obtained during both baseline and test periods. Comparisons of these distributions might reveal whether or not use of the Guide resulted in any changes in detection cues employed.

BAC levels. Measured BAC levels of persons arrested for DWI during the period were obtained for comparison with $B A C$ levels of persons arrested during the baseline period. Enhanced detection of persons owl might be reflected in decreased $B A C$ levels, as officers become more facile in detecting BAC levels closer to the legal impairment level.

DHI detection probabilities. For purposes of the field test, the Guide was modified to permit direct recording of observed cues and the outcome of each detection event. These data provided the basis for calculating DWI detection probabilities associated with each cue or cue combination, for comparison to Guide values.

Police officer opinions and suggestions. Opinions and suggestions were obtained from groups of officers about midway through the three-month test period. Responses were obtained by means of group interviews conducted by project"staff members during agency visits. 


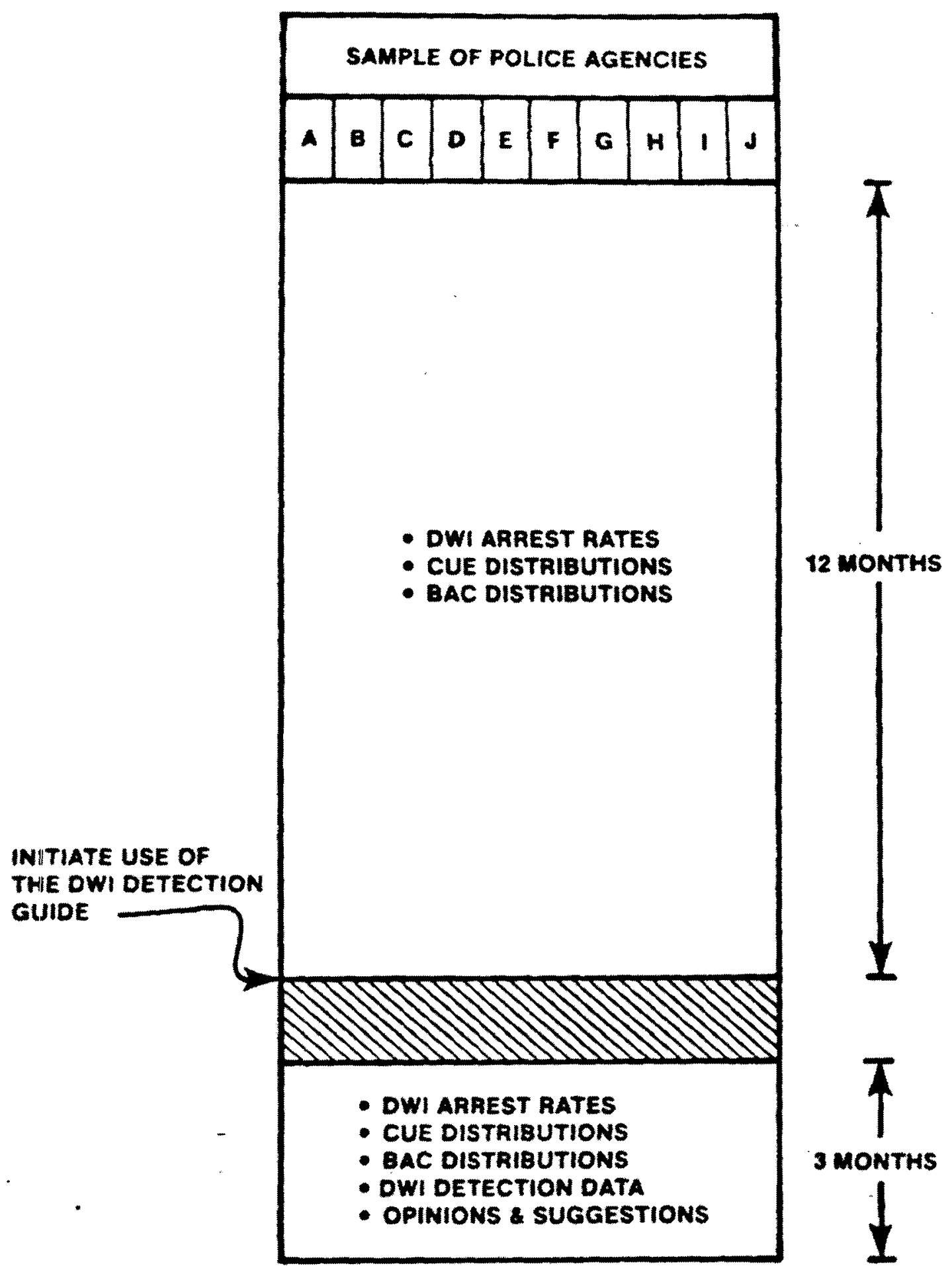

Flgure 1. Field study experimental desion. 


\section{PARTICIPATING AGEMCIES}

The 10 law enforcement agencies selected for participation in the study are listed below, along with the populations served by each agency. as estimated by the 1970 census. Agencies are listed in alphabetical order:
Albuquerque (New Mexico) Police Department
243,751
Englewood (Colorado) Police Department
33,695
Eugene (Oregon) Police Department
76,346
Evansville (Indiana) Police Department
138,764
Monroe County (New York) Sheriff's Office
711,917
Pulaski County (Arkansas) Sheriff's Office
287,189
Santa Ana (California) Folice Department
156,601
Tacoma (Washington) Police Department
154,581
Topeka (Kansas) Police Department.
125,011
Vanderburgh County (Indiana) Sheriff's office
168,772
Within the 10 agencies, data were collected from different types of police patrols: nine agencies employed general patrols responsible for criminal and traffic enforcement and/or traffic patrols responsible for traffic enforcement; two agencies had DWI patrols responsible primarily for DWI enforcement; and one agency had a selective traffic patrol respons- ible for DWI and speeding enforcement. A total of 466 patrol officers participated.

\section{FIELD-TEST PROCEDURES}

The field test consisted of seven major tasks conducted sequen:ially. Each task is sumarized and discussed in the following paragraphs. 


\section{Preparation of Guide and Materials}

Alternative formats for the Drunk Driver Detection Guide were developed and exposed to samples of police officers who had participated earlier in the research. After consideration of the opinions and suggestions received, final specifications for the Guide were prepared. The resulting Guide is described and illustrated in the Appendix." To accompany and explain the Guide a booklet, "Drunk Driver Detection: An Explanation of the Drunk Driver Detection Guide," was prepared and printed. The book let is also presented in the Appendix.

For collecting information for Guide verification, a special record form was designed for use during the three-month test period. This form enabled the police officer to check the cues observed, record est imated $B A C$ levels, and indicate the disposition of the apprehended driver. Sets of 25 forms were combined into a $10.16 \mathrm{~cm} \times 20.96 \mathrm{~cm}$ (4 inches $\times 8 \frac{1}{4}$ inches) pad. The form was about the size of most citation books to facilitate handling. As a form was completed and removed for submittal to Anacapa, a new form was exposed for recording the next detection event. The form is illustrated in Figure 2.

\section{Arrangement of Agency Participation}

Ten law enforcement agencies were selected for participation in the study. A list of the participating agencies along with the size populations they served was presented earlier. Agency selection was made in atcordance with the following criteria.

- Geographical dispersion throughout the United States, agencies from the West, North, East, South and Central regions of the country.

- Agency-interest in enforcing statutes which prohibit DWI, although special DWI patrols or practices were not required.

- Agency willingness to cooperate in accordance with the requirements of the study. 
DRUNK DRIVER DETECTIDN GUIDE AKD RECORD FORM

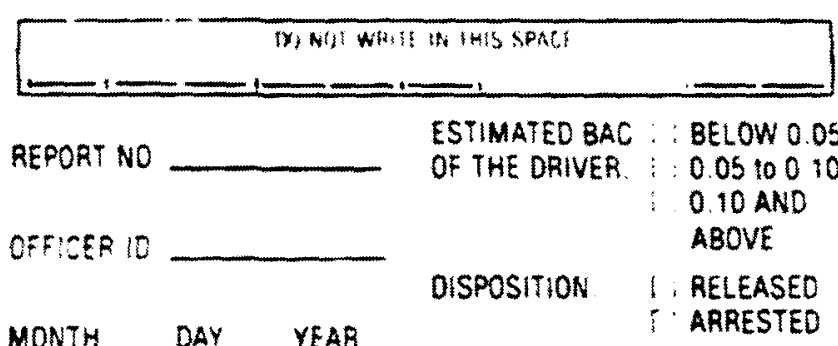

MONTH DaY YEAR

RELEASED

Chect

aporoorate

bexies:

Percentage of nonitume dints with

Visual Cues

$$
\text { Visual Cues }
$$

102. FOLLOUNG TOO CLOSELY

103. TURNING WTH WIOE RADIUS $\ldots \ldots \ldots \ldots \ldots \ldots \ldots$

104: APPEARING TO BE DRUNK ..............

10: ORIVIKG ON OTHEA THAN OESIGNATED ROAOUYY

10\%, STRLDDLING CEHTER OR LANE NARKER . . . . . . . SS

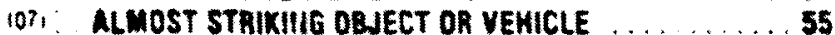

108: ' SLOW RESPONSE TO TRAFFIC SIGNALS . . . . . . . so

109: HEADLGHTS OFF [AT NIGHT] . . . . . . . . . 50

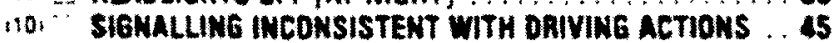

,$\because$, WENVING $\ldots \ldots \ldots \ldots \ldots \ldots$

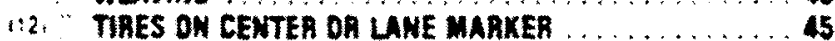

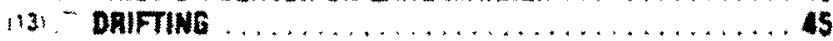

114: SWERVING $\ldots \ldots \ldots \ldots \ldots \ldots \ldots \ldots$

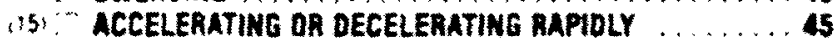

¿16: SLOW SPEED (MDRE THAN 10 MPH BELOW LMIT) . . . S

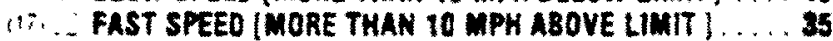

18. FAILING TO RESPOND TO TRAFFIC SIGNALS OR SIGNS . ss

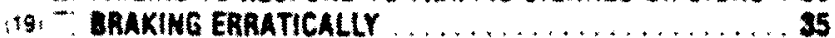

120. - STOPPNG INAPPROPRIATELY (OTHER THAN IN LNNE] , SS

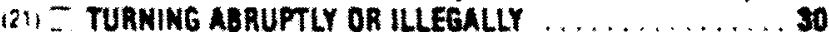

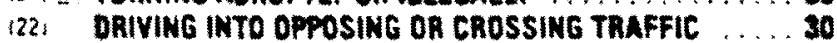

123. DRIVING WTHK VEHICLE DEFECTIS] ..........., an

174. GTHER

\section{Special Adjustments to the Percentages}

- 2 cues. Ado 5 to the large: percentage

- 3 or more cues ado 10 to the arges percentage

- To predic: BAC cqual to or greater than 05. A60 20 to the per. centage oblaned tor arwers wh BAC equal to or greater than 10

Figure 2. Form for recording detection ovents. 
Formal contact was made initially by mail with four agencies in each NHTSA region, followed by telephone contact with those responding. Visits were then made to the 13 agencies that appeared to be most promising. The final 10 were selected on the basis of what was learned during the visits regarding agency interest and willingness. The effort was closely coordinated with the Contract Technical Manager, cognizant personnel of Traffic Safety Programs, and NHTSA Regional Coordinators.

\section{Collection of Baseline Data}

Three types of baseline data were collected from each agency--number of DWI arrests, frequencies of reported cues, and BAC levels of arrested drivers. All reports of DWI arrests over the 12-month baseline period were reviewed, and the required data abstracted from them. In addition, a month-by-month tabulation of the number of person-hours of patrol activity was recorded. This information was used to calculate DWI arrest rate, number of DWI arrests per 100 person-hours of patrol activity.

\section{Initiation of Guide Use}

During the month prior to the three-month test period, training was conducted to introduce the Guide to the 466 participating patrol officers within the 10 agencies. The training required about 30 minutes and, in many cases was conducted during roll-call or routine briefing sessions. Although the Guide itself was relatively self-explanatory, the training sessions provided an opportunity to:

- Explain the empirical basis for the Guide, sumarizing the research that went into its development.

- Assure that the three-step detection process and the underlying concepts of probability were understood.

- Provide an opportunity to clarify definitions of the visual detection cues and distinctions anong them.

- Answer questions concerning the Guide and its use. 
- Explain the purpose of recording detection events and the use of the Drunk Oriver Detection Guide and Record Form including instructions for submitting completed sheets to Anacapa.

\section{Data Collection}

During the three-month field-test and data-collection period, arrest-rate, cue-frequency, and $B A C$-level data were collected in the same manner as the baseline data were collected earlier.

DWI detection-event data were collected by means of the detection report forms discussed earlier and shown in Figure 1. These forms were kept in the patrol vehicle by each patrol officer; one form was completed for each detection event. Completed forms were then given to a designated member of the agency who either held them for collection by an Anacapa staff member or forwarded them by mail to Anacapa.

Police opinions and suggestions concerning the use of the Guide were obtained during group discussions, about midway through the three-month period. Opportunity and encouragement were provided for the group to cover any topic related to the Guide. Topics covered in each session were, at a minimum:

- How useful has the Guide been to you in the enforcement of DWI?

- Specifically, what advantages and disadvantages have you found in using the guide?

- What specific suggestions do you have for improving the Guide and increasing its usefulness?

During the data-collection period, project staff members visited each agency about three times to assure that data were being collected properly.

6. Data Analys is -

Consistent with the four field-test objectives and the types of data collected, the data-analys is effort consisted of the following four parts: 
Comparisons of DUI arrest rates. Arrest rates (number of DWI. arrests per 100 person-hours of patrol) were calculated monthly for each of the ten police agencies, and patrol types within agencies, for each of the 12 months prior to and for each of the three months following initiation of the use of the Guide. These data were charted and comparisons made between baseline and test periods. Baseline-test comparisons were made for individual agencies and patrols for the total sample of agencies and patrols, and for types of patrols. Statistical tests were conducted using both and lys is of variance (ANOVA) and $x^{2}$.

Comarisons of cues and BAC levels. Comparisons were made between baseline and test periods for: number of cues employed, frequency distributions of cues reported, and mean BAC levels of drivers arrested. Statistical tests were made using $x^{2}$ and $t$ sampling distributions to determine the significance of any differences found in these variables between baseline and test periods.

Guide verification. DWl probability values were calculated from field data for each cue, under each cue occurrence possibility (one of one or more cues, one of two or more cues, or one of three or more cues), and compared with DWI probability values obtained from the Guide.

Tabulation of patrol officer opinions and suggestions. A content analysis was completed of responses recorded from group discussions regarding utility of the Guide. Responses were classified and tabulated; notation was made regarding whether or not there was group consensus for each opinion or suggestion made.

\section{Preparation of Final Report}

The findings resulting from the four components of the field-test data collection and andys is effort were integrated and interpreted in terms of their implication for the modification and future use of the Guide. The study was then described and the results presented in this report. 


\section{RESULTS}

Use of the Drunk Driver Detection Guide was accompanied by a significant increase in DWI arrest rate. However, use of the Guide was not accompanied by increases in the number of cues reported per DWI arrest, changes in cue emphasis, or reductions in BAC levels of drivers arrested.

The probability values contained in the Guide were verified by field-test results. Average Guide and field-test values were not significantly different for either $P(B A C \geq .10)$ or $P(B A C \geq .05)$. Field-test probability values for individual cues correlated significantly with Guide probability values.

Police officers who used the Guide expressed doubts about its value for increasing their own ability to detect DWI. However, they considered the Guide to be a valuable aid for increasing patrol awareness of useful cues, training inexperienced patrol officers, preparing owI arrest reports, and supporting court testimony.

\section{IPPACT ON DUI ARREST RATES}

Collectively, for all 10 participating agencies, DWI arrest rate was 12 percent higher during the test period than during the baseline period. This difference was statistically significant $(p<.01)$. Comparison of baseline and test periods is shown graphically in Figure 3. Individually, five agencies had DWI arrest rates significantly higher during the test period; one had a significantly lower rate; and four had rates that remained essentially unchanged.

Arrest rate was defined and calculated as the number of DWI arrests made per 100 person-hours of patrol activity. During the entire 15-month period, a total of 5348 arrests were made during a total of 788,200 personhours of patrol. Arrest rates are provided in Table 1 for each agency, for the 12-month baseline period and three-month test period, along with the numbers of arrests and person-hours of patrol activity from which they 


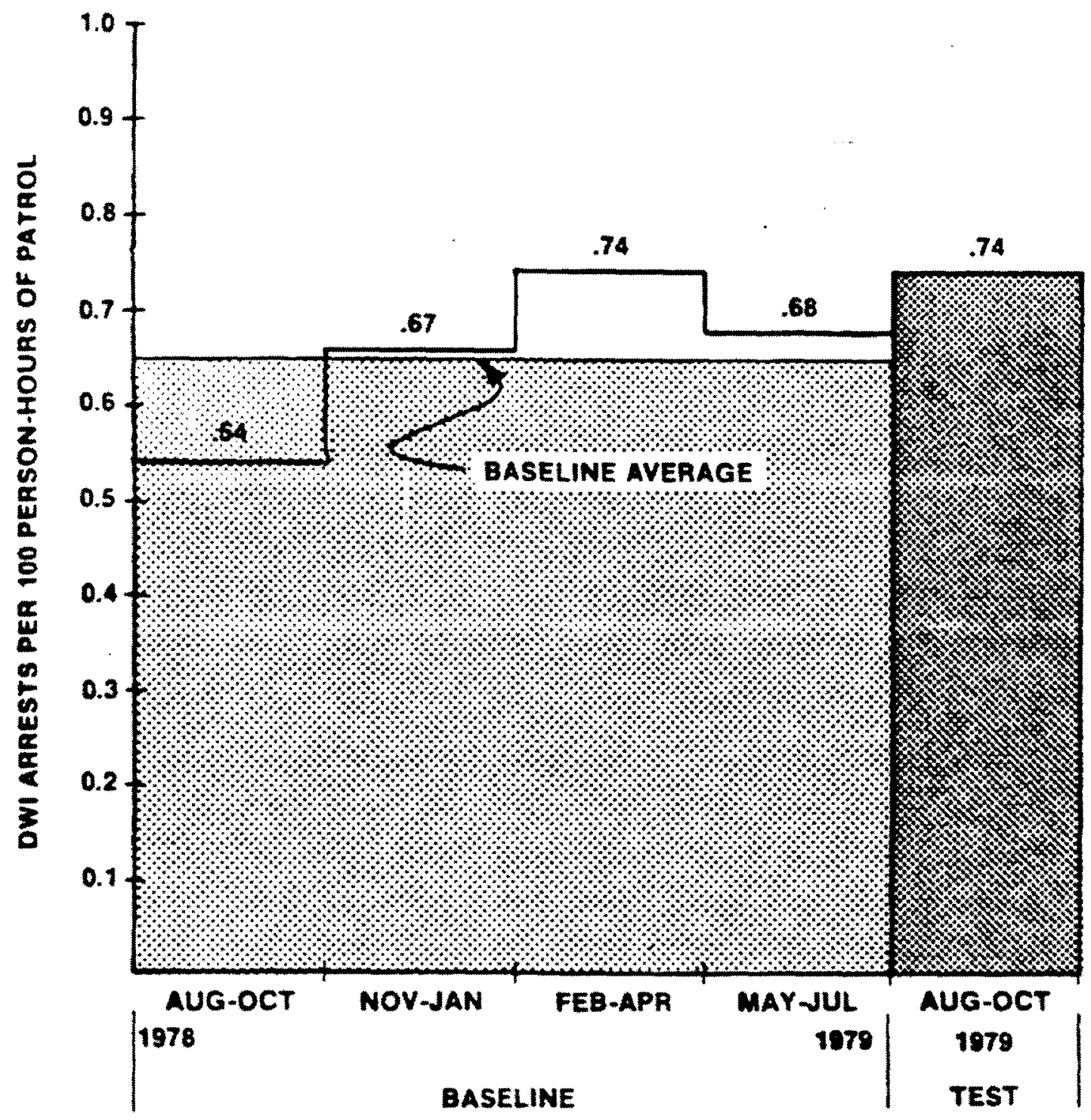

Figure 3. Quarterly DWI arrest rates for all ten participating agencies during baseline and test periods. 
TABLE 1

DWI Arrests per 100 Person-Hours of Patrol

During Baseline and Test Periods by Agency

\begin{tabular}{|c|c|c|c|c|c|c|c|c|}
\hline \multirow[b]{2}{*}{ AGENCY } & \multicolumn{3}{|c|}{ BASELINE PERIOD } & \multicolumn{3}{|c|}{ TEST PERIOD } & \multirow[b]{2}{*}{${ }_{\text {CHANGE }}^{*}$} & \multirow[b]{2}{*}{$x^{2}$} \\
\hline & $\begin{array}{c}\text { DWI } \\
\text { ARRESTS }\end{array}$ & $\begin{array}{l}\text { PATROL } \\
100 \text { HRS. }\end{array}$ & $\begin{array}{l}\text { ARREST } \\
\text { RATE }\end{array}$ & $\begin{array}{c}\text { DWI } \\
\text { ARRESTS }\end{array}$ & $\begin{array}{l}\text { PATROL } \\
100 \text { HRS. }\end{array}$ & $\begin{array}{l}\text { ARREST } \\
\text { RATE }\end{array}$ & & \\
\hline$A$ & 2017 & 1387 & 1.45 & 379 & 369 & 1.03 & -29 & $38.68^{*}$ \\
\hline B & 319 & 641 & .50 & 135 & 150 & .90 & +80 & $34.44 *$ \\
\hline$c$ & 150 & 639 & .23 & 67 & 171 & .39 & +70 & $12.17^{\star}$ \\
\hline$D$ & 234 & 1346 & .17 & 109 & 331 & .33 & +94 & $30.83^{*}$ \\
\hline$E$ & 66 & 269 & .25 & 14 & 65 & .22 & -12 & .31 \\
\hline$F$ & 148 & 728 & .23 & 30 & 176 & .17 & -15 & .88 \\
\hline G & 65 & 102 & .64 & 13 & 25 & .52 & -19 & .33 \\
\hline$H$ & 530 & 68 & 7.79 & 217 & 16 & 13.56 & +74 & $48.91 *$ \\
\hline 1 & 130 & 362 & .36 & 28 & 93 & .30 & -17 & .63 \\
\hline J & 526 & 758 & .69 & 171 & 186 & .92 & +33 & $10.50 *$ \\
\hline TOTAL & 4185 & 6300 & .66 & 1163 & 1582 & .74 & +12 & $10.57 *$ \\
\hline
\end{tabular}

$\star^{*} p<.01$

were calculated. The statistical significance of differences in arrest rates between baseline and test periods were tested by means of the $x^{2}$ sampling distribution. Agencies are identified by randomily assigned letter for presentation of the results.

Some of the differences among agencies in magnitude of DWI arrest rates were function of the types of enforcement patrols employed. The types of patrols included in the field study were: general patrols responsible for the full range of criminal and traffic enforcement 
activities, traffic patrols responsible for the full range of traffic enforcement, OWI patrols responsible mainly for DWl detection and arrest, and a selective traffic patrol responsible for DWI and speeding enforcement. Within nine agencies data were collected from general and/or traffic patrols (GENERAL); within two agencies data were collected from CWI patrols (DWI); and within one agency data were collected from a selective traffic patrol (SELECTIVE). Agency $A$ had general and DWI patrols; Agency $J$ had general and selective patrols; and data were collected only from DWI patrols in Agency $H$. In Agencies $A$ and $J$, the percentage changes in DWI arrest rate from baseline to test periods were comparable between the two patrol types; thus, data from both types of patrol were combined for these two agencies in Table 1.

Arrest rates are showr in Table 2 for each type of patrol. There were significant increases in arrest rate from baseline to test periods for general and selective traffic patrols, but not for DWI patrols. The DWI. patrol of Agency A had a statistically significant $(p<.01) 27$ percent decrease in arrest rate, from 18.50 to 13.50 while the DWI patrol of Agency $H$ had a statistically significant $(p<.01) 74$ percent increase from 7.79 to 13.56 . The decrease in one cancelled the increase in the other, resulting in a small increase overall that was not statistically significant.

Striking differences among arrest rates for the three types of patrols are also reflected in Table 2. Arrest rate of selective traffic patrols was about four times that of general patrols; arrest rate of DWI patrols was about 30 times that of general patrols, and eight times that of the selective traffic patrol. From another perspective, these data revealed that one DWI arrest was made for each eight hours of DWI patrol, 70 hours of selective traffic patrol, or 260 hours of general patrol.

\section{CHANGES IN DWI DETECTION PRACTICES}

There were no statistically significant differences between baseline and test periods on any of three measures that might have reflected 
TABLE 2

DWl Arrests per 100 Person-Hours of Patrol

During Baseline and Test Periods by Patrol Type

\begin{tabular}{|c|c|c|c|c|c|c|c|c|}
\hline \multirow[b]{2}{*}{$\begin{array}{l}\text { PATROL } \\
\text { TYPE }\end{array}$} & \multicolumn{3}{|c|}{ BASELINE PERIOD } & \multicolumn{3}{|c|}{ TEST PERIOD } & \multirow[b]{2}{*}{$\begin{array}{c}* \\
\text { CHANGE }\end{array}$} & \multirow[b]{2}{*}{$x^{2}$} \\
\hline & $\begin{array}{c}\text { DWI } \\
\text { ARRESTS }\end{array}$ & $\begin{array}{l}\text { PATROL } \\
100 \mathrm{HRS} \text {. }\end{array}$ & $\begin{array}{c}\text { ARREST } \\
\text { RATE }\end{array}$ & $\begin{array}{c}\text { DWI } \\
\text { ARRESTS }\end{array}$ & $\begin{array}{l}\text { PATROL } \\
100 \mathrm{HRS} \text {. }\end{array}$ & $\begin{array}{l}\text { ARREST } \\
\text { RATE }\end{array}$ & & \\
\hline GEHERAL & 2277 & 5967 & .38 & 636 & 1504 & .42 & +16 & $5.34 *$ \\
\hline SELECTIVE & 299 & 208 & 1.44 & 94 & 46 & 2.04 & +42 & $31.60 * *$ \\
\hline DinI & 1582 & 125 & 12.66 & 433 & 32 & 13.53 & +07 & 1.48 \\
\hline TOTAL & 4158 & 6300 & .66 & 1163 & 1582 & .74 & +12 & $10.57 * *$ \\
\hline
\end{tabular}

$\star p<.05$

$* * 0<.01$

changes in DWI detection practices. The number of visual detection cues recorded per arrest did not increase; a significant shift to the use of higher probability cues did not occur; and the BAC levels of persons arrested did not decrease significantly.

As shown in Table 3, about 2.0 cues were recorded on DWI arrest reports, on the average, over the 10 agencies during both baseline and test periods. Although larger differences were found among individual agencies, most of which were increases, none was statistically significant at $p<.05$.

The relative frequencies with which detection cues were reported on DWI arrest reports were very stable and relatively unaffected by use of the Guide. Table 4 shows the frequency distributions of detection cues recorded during both baseline and test periods. To permit direct comparison, the distributions shown were based on the number of occurrences of each cue for 1000 total cue occurrences. Inspection of the two distributions reveals that they are nearly identical. 
TABLE 3

Mean Number of Cues Reported per DWI Arrest During Baseline and Test Periods by Agency

\begin{tabular}{c|rc|rr|c}
\hline & BASELINE & PER10D & \multicolumn{2}{|c|}{ TEST PER 100} & \\
AGENCY & NUMBER & MEAN & NUMBER & MEAN & $\%$ \\
ARRESTS & CUES & ARRESTS & CUES & CHANGE \\
\hline A & 2017 & 2.35 & 379 & 2.41 & +02 \\
B & 319 & 2.01 & 135 & 2.16 & +07 \\
C & 150 & 1.38 & 67 & 1.55 & +12 \\
D & 234 & 1.78 & 109 & 1.74 & -02 \\
E & 66 & 1.47 & 14 & 1.33 & -09 \\
F & 148 & 2.43 & 30 & 3.37 & +39 \\
G & 65 & 2.56 & 13 & 2.75 & +07 \\
H & 530 & 1.92 & 217 & 1.78 & -07 \\
I & 130 & 1.83 & 28 & 1.90 & +04 \\
J & 526 & 1.19 & 171 & 1.26 & +06 \\
TOTAL & 4185 & 2.03 & 1163 & 1.99 & -02 \\
\hline
\end{tabular}

The product-moment correlation between the two is .98 , statistically significant beyond $p<.01$. There was some shift in frequencies toward the higher probability cues during the test period but this was not statistically significant. The 10 cues with highest DWI probabilities occurred 8 percent more frequently in the test period while the 10 cues with lowest Dwl probability occurred 9 percent less frequently.

Although the mean BAC of persons arrested for DWI decreased from the baseline period to the test period in 9 of 10 agencies, the amount of the decrease was not statistically significant. These results are presented in Table 5 .

\section{VERIFICATION OF THE GUIDE}

Probability values contained in the Guide were verified by the proportions of drivers apprehended during the field test wo were found 
TABLE 4

Frequency Distributions of Detection Cues Recorded on

DWI Arrest Reports During Baseline and Test Periods

\begin{tabular}{|c|c|c|c|}
\hline \multicolumn{2}{|r|}{ DETECTION CUE } & \multicolumn{2}{|c|}{$\begin{array}{l}\text { OCCURRENCE } \\
\text { (TIMES IN 1000) } \\
\text { BASELINE TEST }\end{array}$} \\
\hline 1 & Stopping (without cause) in traffic lane & 17 & 13 \\
\hline 2 & Following too closely & 5 & 5 \\
\hline 3 & Turning with wide radius & 23 & 25 \\
\hline 4 & Appearing to be drunk & 21 & 21 \\
\hline 5 & Driving on other than designated roadway & 32 & 29 \\
\hline 6 & Straddiing center or lane marker & 62 & 61 \\
\hline 7 & Almost striking object or vehicle & $\cdot 62$ & 72 \\
\hline 8 & Slow response to traffic signals & $\cdot 7$ & 10 \\
\hline 9 & Headlights off (at night) & 22 & 29 \\
\hline 10 & Signalling inconsistent with driving actions & 17 & 23 \\
\hline 11 & Weaving & 145 & 156 \\
\hline 12 & Tires on center or lane marker & 4 & 5 \\
\hline 13 & Drifting & 31 & 24 \\
\hline 14 & Swerving & 49 & 35 \\
\hline 15 & Accelerating or decelerating rapidly & 57 & 41 \\
\hline 16 & Slow speed--more than $10 \mathrm{MPH}$ below limit & 40 & 32 \\
\hline 17 & Fast speed--more than $10 \mathrm{MPH}$ above limit & 129 & 130 \\
\hline 18 & Failing to respond to traffic signals or signs & $\cdot 73$ & 83 \\
\hline 19 & Braking erratically & $\cdot 9$ & 10 \\
\hline 20 & Stopping inappropriately other than in lane & 25 & 23 \\
\hline 21 & Turning abruptly or illegally & 60 & 37 \\
\hline 22 & Driving into opposing or crossing traffic & 52 & 56 \\
\hline 23 & Driving with vehicle defect(s) & 17 & 21 \\
\hline
\end{tabular}


TABLE 5

Mean BAC of Persons Arrested During Baseline and Test Perjods by Agency

\begin{tabular}{|c|c|c|c|c|c|}
\hline \multirow[b]{2}{*}{ AGENCY } & \multicolumn{2}{|c|}{ BASELINE PERIOD } & \multicolumn{2}{|c|}{ TEST PERIOD } & \multirow[b]{2}{*}{$\stackrel{\%}{\%}$ CHANGE } \\
\hline & $\begin{array}{l}\text { NUMBER } \\
\text { ARRESTS }\end{array}$ & $\begin{array}{l}\text { MEAN } \\
\text { BAC }\end{array}$ & $\begin{array}{l}\text { NUMBER } \\
\text { ARRESTS }\end{array}$ & $\begin{array}{l}\text { MEAN } \\
\text { BAC }\end{array}$ & \\
\hline A & 1820 & .163 & 313 & .162 & -01 \\
\hline B & 210 & .181 & 88 & .175 & -04 \\
\hline C & 132 & .182 & 57 & .168 & -08 \\
\hline 0 & 177 & .189 & 89 & .192 & +02 \\
\hline$E$ & 52 & .193 & 12 & .187 & -03 \\
\hline$F$ & 80 & .178 & 19 & .171 & -03 \\
\hline 6 & 65 & .181 & 11 & .170 & -06 \\
\hline$H$ & 530 & .174 & 210 & .167 & -04 \\
\hline 1 & 84 & .160 & 19 & .137 & -14 \\
\hline J & 475 & .154 & 153 & .144 & -06 \\
\hline TOTAL & $3625 \star$ & .167 & $971 *$ & .164 & -02 \\
\hline
\end{tabular}

* Differs from total numbers of arrests because BAC was not obtained for every person arrested.

to have BAC levels of equal to or greater than .05 and .10 . Average Guide probability values over all cues were essentially the same as the overall probabilities calculated from field-test data. Figure 4 shows comparisons of Guide and test values for $P(B A C \geq .05)$ and $P(B A C \geq .10)$ when the observed cue was one of one or more cues, one of two or more cues, and one of three or more cues.

Correlations between Guide DWI probabilities and test DWI probabilities for individual cues were statistically significant $(p<.05)$ in all cases. Comparisons of Guide and test values are presented in Tables 6 and 7. Comparison of Guide and test values must be made in light of two important considerations. First, the probabilities contained in the Guide 

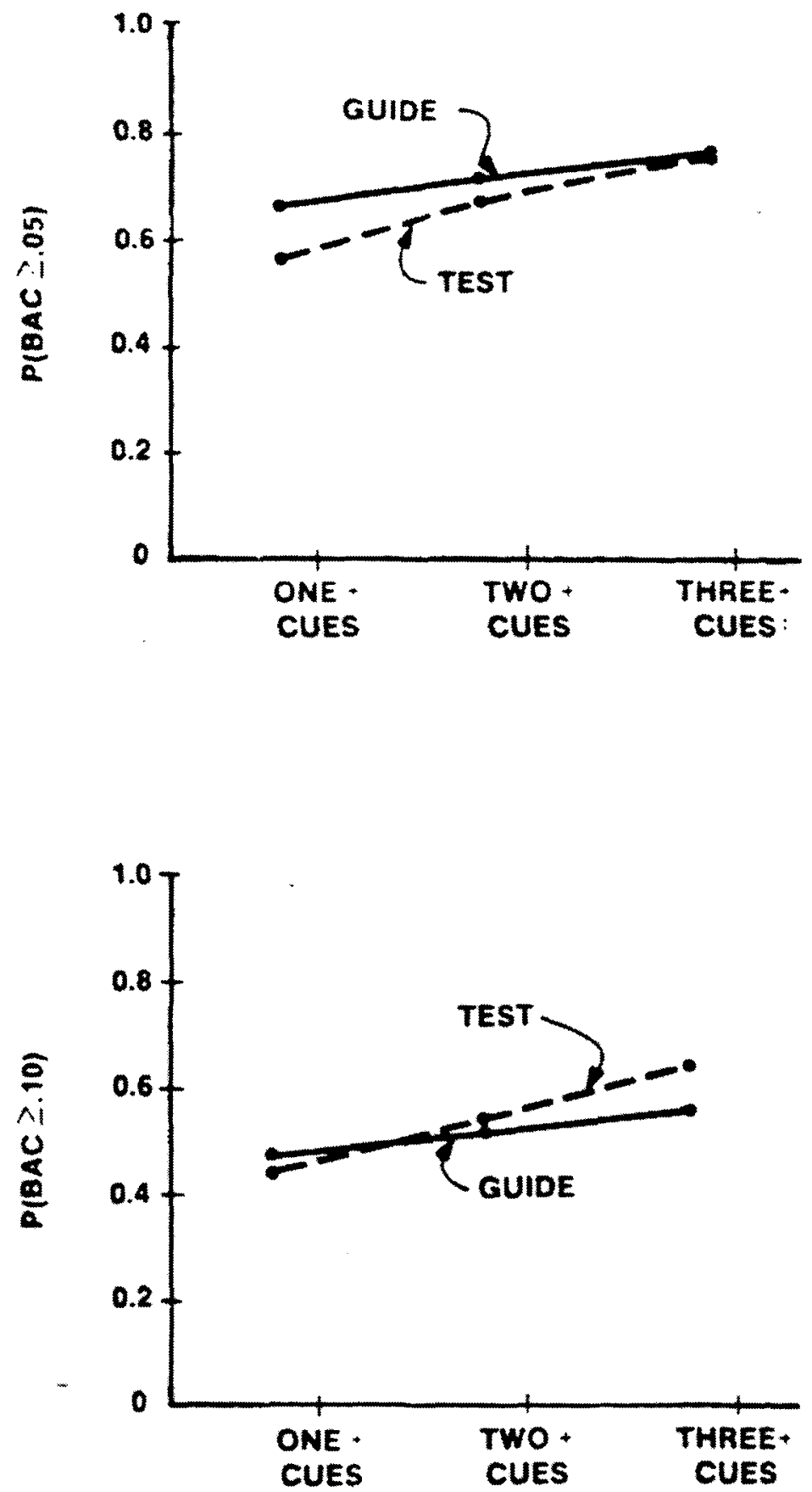

Figure 4. Comparison of average cue probablity values of the Guide with those calculated from the field test. 
TABLE 6

Comparison of Cue Probability Values of Detection Guide with values Obtained from field-Test Data for $P(B A C \geq .10)$

\begin{tabular}{|c|c|c|c|c|c|c|c|}
\hline \multirow{3}{*}{\multicolumn{2}{|c|}{ DETECTION CUE }} & \multicolumn{6}{|c|}{$\begin{array}{l}\text { P(BAC } \geq .10) \\
\text { WHEN CUE OBSERVED AS ONE OF: }\end{array}$} \\
\hline & & \multirow{2}{*}{\multicolumn{2}{|c|}{$\begin{array}{c}\text { ONE OR } \\
\text { MORE CUES } \\
\text { GUIDE TEST }\end{array}$}} & \multirow{2}{*}{\multicolumn{2}{|c|}{$\begin{array}{c}\text { TWO OR } \\
\text { MORE CUES } \\
\text { GUIDE TEST }\end{array}$}} & \multirow{2}{*}{\multicolumn{2}{|c|}{$\begin{array}{l}\text { THREE OR } \\
\text { MORE CUES } \\
\text { GUIDE TEST }\end{array}$}} \\
\hline & & & & & & & \\
\hline 1 & Stopping (without cause) in traffic lane & .70 & .42 & .75 & .75 & .80 & .83 \\
\hline 2 & Following too closely & .60 & .38 & .65 & .44 & .70 & .53 \\
\hline 3 & Turning with wide radius & .60 & .64 & .65 & .64 & .70 & .72 \\
\hline 4 & Appearing to be drunk & .60 & .61 & .65 & .65 & .70 & .75 \\
\hline 5 & Driving on other than designated roadway & .55 & .56 & .60 & .64 & .65 & .76 \\
\hline 6 & Straddling center or lane marker & .55 & .64 & .60 & .67 & .65 & .68 \\
\hline 7 & Almost striking object or vehicle & .55 & .65 & .60 & .71 & .65 & .73 \\
\hline$B$ & Slow response to traffic signals & .50 & .38 & .55 & .64 & .60 & .66 \\
\hline 9 & Headlights off (at night) & .50 & .24 & .55 & .41 & .60 & .54 \\
\hline 10 & Signalling inconsistent with driving actions & .45 & .37 & .50 & .58 & .55 & .73 \\
\hline 11 & Weaving & .45 & .62 & .50 & .67 & .55 & .76 \\
\hline 12 & Tires on center or lane marker & .45 & .46 & .50 & .47 & .55 & .53 \\
\hline 13 & Drifting & .45 & .50 & .50 & .54 & .55 & .65 \\
\hline 14 & Swerving & .45 & .57 & .50 & .61 & .55 & .66 \\
\hline 15 & Accelerating or decelerating rapidly & .45 & .26 & .50 & .34 & .55 & .52 \\
\hline 16 & Slow speed (more than $10 \mathrm{MPH}$ below limit) & .45 & .52 & .50 & .65 & .55 & .70 \\
\hline 17 & Fast speed (more than $10 \mathrm{MPH}$ above limit) & .35 & .13 & .40 & .49 & .45 & .59 \\
\hline 18 & Failing to respond to traffic signals or signs & .35 & .15 & .40 & .39 & .45 & .60 \\
\hline 19 & Braking erratically & .35 & .52 & .40 & .56 & .45 & .59 \\
\hline 20 & Stopping inappropriately other than in lane & .35 & .41 & .40 & .52 & .45 & .67 \\
\hline 21 & Turning abruptly or illegally & .30 & .34 & .35 & .53 & .40 & .54 \\
\hline 22 & Driving into opposing or crossing traffic & .30 & .50 & .35 & .58 & .40 & .67 \\
\hline \multirow[t]{3}{*}{23} & Driving with vehicle defect(s) & .30 & .06 & .35 & .21 & .40 & .44 \\
\hline & AVERAGE & .46 & .43 & .51 & .55 & .56 & .65 \\
\hline & $\begin{array}{l}\text { Coefficient of correlation between } \\
\text { Guide and test }\end{array}$ & & \multicolumn{2}{|c|}{.54} & \multicolumn{2}{|c|}{.54} \\
\hline
\end{tabular}




\section{TABLE 7}

Comparison of Cue Probability Values of Detection Guide with Values obtained from Field-Test Data for $P(B A C \geq .05)$

\begin{tabular}{|c|c|c|c|c|c|c|c|}
\hline \multirow{3}{*}{\multicolumn{2}{|c|}{ DETECTION CUE }} & \multicolumn{6}{|c|}{$\begin{array}{l}P(B A C \geq .05) \\
\text { WHEN CUE OBSERVED AS ONE OF: }\end{array}$} \\
\hline & & \multirow{2}{*}{\multicolumn{2}{|c|}{$\begin{array}{c}\text { ONE OR } \\
\text { MORE CUES } \\
\text { GUIDE TEST }\end{array}$}} & \multirow{2}{*}{\multicolumn{2}{|c|}{$\begin{array}{l}\text { TWO OR } \\
\text { MORE CUES } \\
\text { GUIDE TEST }\end{array}$}} & \multirow{2}{*}{\multicolumn{2}{|c|}{$\begin{array}{l}\text { THREE OR } \\
\text { MORE CUES } \\
\text { GUIDE TEST }\end{array}$}} \\
\hline & & & & & & & \\
\hline 1 & Stopping (without cause) in traffic lane & .90 & .51 & .95 & .80 & 1.00 & .92 \\
\hline 2 & Following too closely & .80 & .62 & .85 & .63 & .90 & .71 \\
\hline 3 & Turning with wide radius & .80 & .79 & .85 & .81 & .90 & .86 \\
\hline 4 & Appearing to be drunk & .80 & .76 & .85 & .76 & .90 & .82 \\
\hline 5 & Driving on other than designated roadway & .75 & .67 & .80 & .77 & .85 & .88 \\
\hline 6 & Straddling center or lane marker & .75 & .78 & .80 & .79 & .85 & .80 \\
\hline 7 & Almost striking object or vehicle & .75 & .76 & .80 & .81 & .85 & .82 \\
\hline 8 & Slow response to traffic signals & .70 & .46 & .75 & .69 & .80 & .68 \\
\hline 9 & Headlights off (at night) & .70 & .36 & .75 & .54 & .80 & .69 \\
\hline 10 & Signalling inconsistent with driving actions & .65 & .39 & .70 & .62 & .75 & .82 \\
\hline 11 & Weaving & .65 & .79 & .70 & .80 & .75 & .85 \\
\hline 12 & Tires on center or lane marker & .65 & .62 & .70 & .61 & .75 & .63 \\
\hline 13 & Drifting & .65 & .72 & .70 & .73 & .75 & .81 \\
\hline 14 & Swerving & .65 & .69 & .70 & .71 & .75 & .76 \\
\hline 15 & Accelerating or decelerating rapidly & .65 & .40 & .70 & .47 & .75 & .62 \\
\hline 16 & Slow speed (more than $10 \mathrm{MPH}$ below limit) & .65 & .67 & .70 & .80 & .75 & .78 \\
\hline 17 & Fast speed (more than $10 \mathrm{MPH}$ above limit) & .55 & .20 & .60 & .66 & .65 & .74 \\
\hline 18 & Failing to respond to traffic signals or signs & .55 & .25 & .60 & .55 & .65 & .72 \\
\hline 19 & Braking erratically & .55 & .67 & .60 & .72 & .65 & .67 \\
\hline 20 & Stopping inappropriately other than in lane & .55 & .47 & .60 & .57 & .65 & .67 \\
\hline 21 & Turning abruptly or illegally & .50 & .48 & .55 & .65 & .60 & .70 \\
\hline 22 & Driving into opposing or crossing traffic & .50 & .62 & .55 & .72 & .60 & .78 \\
\hline \multirow[t]{3}{*}{23} & Driving with vehicle defect(s) & .50 & .13 & .55 & .38 & .60 & .58 \\
\hline & AVERAGE & .66 & & .71 & .68 & .76 & .75 \\
\hline & $\begin{array}{l}\text { Coefficient of correlation between } \\
\text { Guide and test }\end{array}$ & \multicolumn{2}{|c|}{.48} & \multicolumn{2}{|c|}{.51} & \multicolumn{2}{|c|}{.59} \\
\hline
\end{tabular}


were derived from data collected using procedures that were substantially different from those employed for collecting data in the field test. Guide probabilities were based on data obtained by stopping each driver observed to be exhibiting deviant driving behavior and administering a breath test to the driver. Observers accompanied patrol officers for purposes of recording the data. Field-test probabilities, on the other hand, were obtained from data recorded on special forms during regular patrol by the patrol officers themselves. Some detection procedures, such as the use of raclar to detect fast speed, differed substantially from those used in the earlier study. The three categories of BAC were estimated by the officer each time a driver was apprehended; however, verification of about twothirds of the $B A C \geq .10$ estimates showed them to be 99 percent accurate.

Second, Guide probability values shown in Tables 6 and 7 were obtained directly from the Guide. Thus, they were rounded-off values for $P(E A C \geq .10)$ that were extended to multiple cue conditions and to $P(B A C \geq$ $.05)$ through application of the simple adjustments presented at the bottom of the Guide. Some loss in accuracy is likely to occur in the process. In fact, correlations between field-test values and the actual values obtained from the earlier detection study were somewhat higher in all cases than those shown in Tables 6 and 7 .

During the field study 4019 apprehensions were made and information about each apprehension was recorded on a Drunk Driver Detection Guide and Record Form (see Figure 2). The disposition of the 4019 apprehensions is traced in Figure 5. As shown, $368+742=1110$ drivers had an est imated $B A C=.05$, and 742 had an est imated $B A C \geq .10$. Est imates were ver if ied for 499 of the 742 by results obtained later from chemical tests; 492 of this sample, 99 percent, were found to have a tested $B A C \geq .10$.

Detection data were combined from the earlier detection study ( $N=$ 643 apprehensions) and the field test (N $=4019$ apprehensions) 


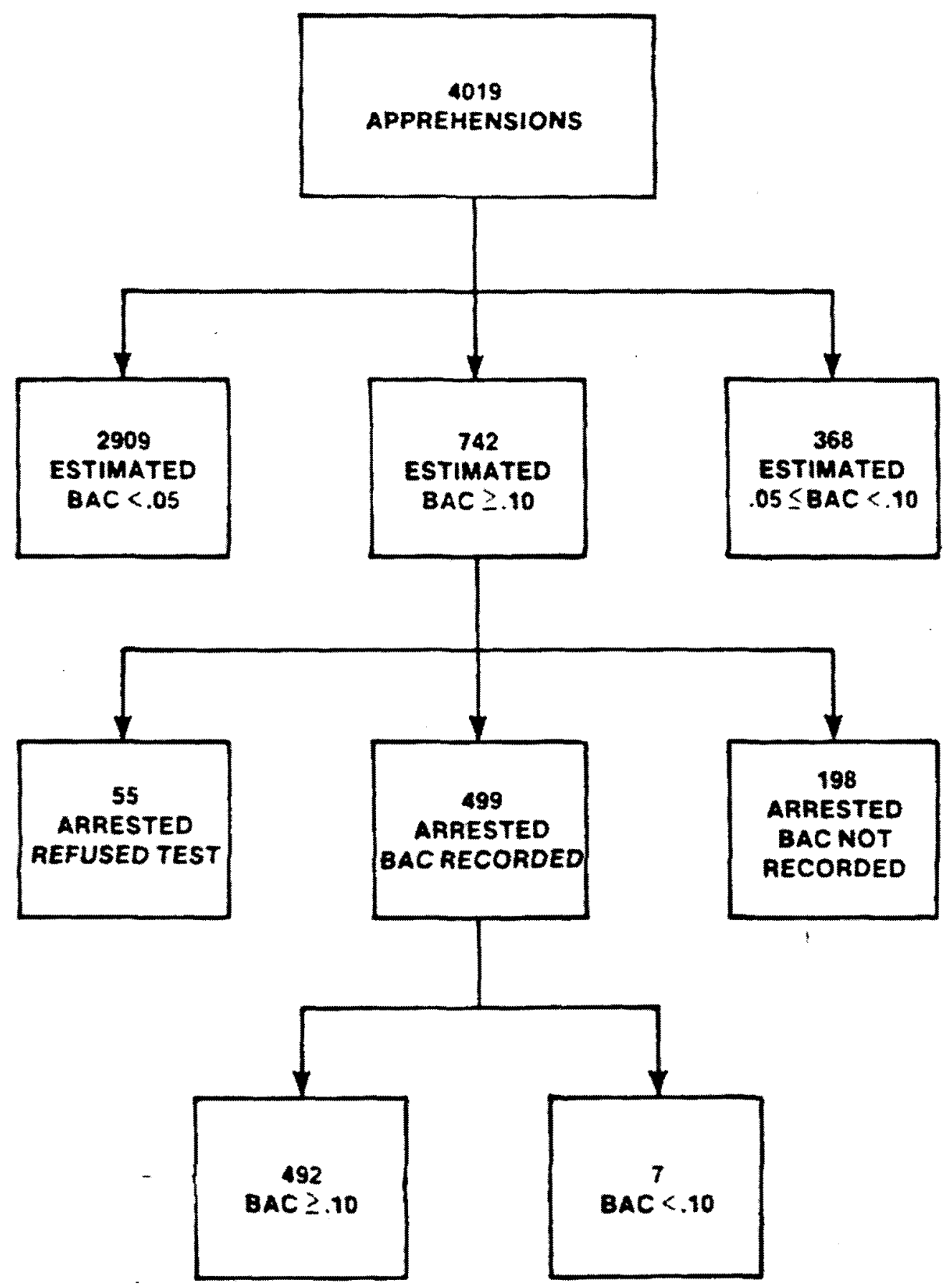

Figure 5. Disposition ol 4019 apprehensions recorded on Drunk Driver Detection Guide and Record Forms during three-month test period. 
to provide new cue discriminability values based upon a substantially larger oata base ( $N=4662$ apprehensions). Because of the larger numeri. cal, geographical, and procedural foundation thus provided by this data base, the resulting probabilities should be more reliable and generalizable than those on the prototype Guide. These values are presented in Tables 8 and 9 . Cues are listed in decreasing order for their new DWI probability values.

\section{OPINIONS OF GUIDE UTILITY}

Experienced police patrol officers were skeptical that use of the Guide would enhance their DWl detection ability. Between four to six weeks after the. Guide was introduced, sample groups of between two to seven patrol officers within each agency were assembled to discuss their experience with the Guide and to obtain their opinions about Guide utility. A more systematic and comprehensive survey of participants was not authorized for the study. A content analysis of the recorded discussions is summarized in Table 10.

Only two of the 10 groups had a consensus that the Guide would help them enhance DWI enforcement; four groups were split on this issue; and four groups had a consensus that the Guide would not enhance DWI enforcement. Perhaps not coincidentally, none of the four agencies with a negative group consensus on this point increased DWI arrest rate during the test period; five of the six agencies in which the group consensus was positive or split increased DWI arrest rate (see Table 1).

In eight of the nine agencies in which there was discussion of the utility of the Guide for increasing patrol sensitivity to important cues, there was a positive or split consensus. There were also generally positive opinions concerning the utility of the Guide as a training aid, as an aid in preparing DWI arrest reports, and as an aid in providing court testimony. Five groups suggested that cue frequency should be incorporated somehow in the Guide; however, three groups were split 
TABLE 8

Cue Discriminability Values Computed from 4662 Detections Made During Detection and Field Studies: $P(B A C \geq .10)$

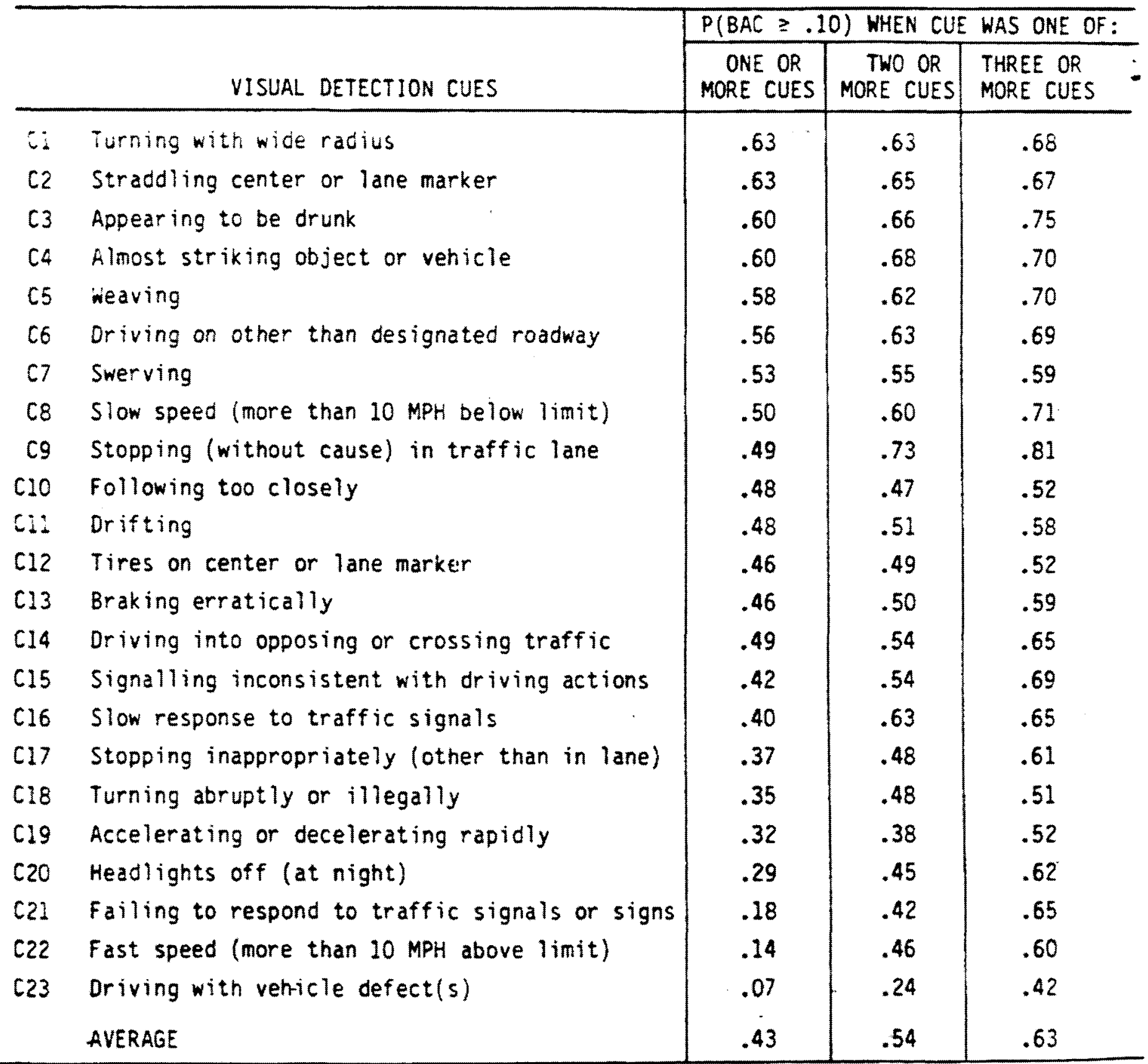


TABLE 9

Cue Discriminability Values Computed from 4662 Detections

Made During Detection and Field Studies: $P(B A C \geq .05)$

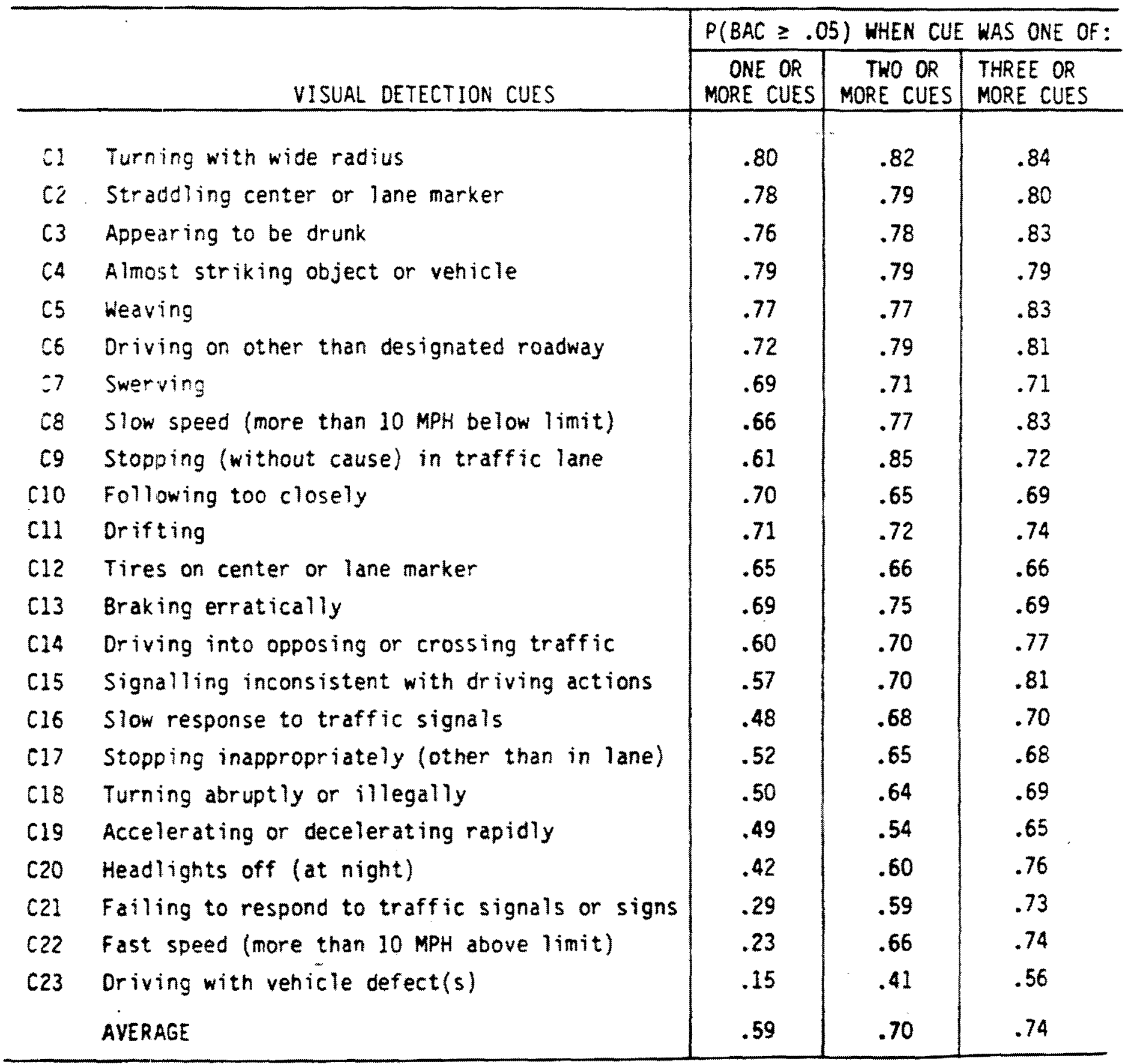


TABLE 10

Summary of the Content Analys is of Group Discussions Conducted at Each Participating Agency Regarding Guide Utility

(Group Consensus: $\quad=$ Positive, $\quad D=$ split, $\quad O=$ Negative)

\begin{tabular}{|c|c|c|c|c|c|c|c|c|c|c|}
\hline \multirow[b]{2}{*}{ TOPIC } & \multicolumn{10}{|c|}{ AGENCY } \\
\hline & A & B & $C$ & D & $E$ & $F$ & G & $H$ & $I$ & $\mathrm{~J}$ \\
\hline $\begin{array}{l}\text { Help enhance DWI } \\
\text { enforcement }\end{array}$ & & & & & & & & & & \\
\hline $\begin{array}{l}\text { Increases sensitivity } \\
\text { to important cues }\end{array}$ & & & & & & & & & & \\
\hline $\begin{array}{l}\text { Helpful as a training } \\
\text { aid }\end{array}$ & & & & & & & & & & \\
\hline $\begin{array}{l}\text { Helpful in reporting } \\
\text { and testifying }\end{array}$ & & & & & & & & & & \\
\hline $\begin{array}{l}\text { Incorporate cue } \\
\text { frequency in Guide }\end{array}$ & & & & & & & & & & \\
\hline
\end{tabular}


in opinion on this suggestion. The following specific changes in the Guide were each recommended by persons in one or two of the ten groups:

- Collapse weaving, drifting, swerving and tires on center or lane marker into one cue.

- Eliminate probability values on the Guide because they might lead to difficulty in court testimony.

- Provide a method for mounting the Guide on a dashboard or visor.

- Put Miranda and DWI warnings on the back of the Guide. 


\section{CONCLUSIONS AND RECOMMENDATIONS}

The utility of the Drunk Driver Detection Guide for on-the-road detection of DWI was demonstrated in the field study. Use of the Guide resulted in an overall increase in DWI arrest rate of 12 percent. This increase took place in a field-test sample that included 10 different police agencies located throughout the United States, that employed different types of patrols, that included a wide range of geographic and traffic conditions, and that reflected different levels of motivation for DWl enforcement. Although there were no statistically significant changes in detection practices, such as those revealed by greater use of the more discriminating cues or by arrests of more drivers with lower BAC levels, trends were in the expected directions.

The DWI probability values associated with the cues contained in the Guide were verified by field-test results, providing a basis for using Guide values with confidence. Although some modifications in Guide values were indicated, the overall result was one of verifying the average probability levels as well as the values for individual cues. Average probability values calculated from field-study data were essentially the same as average Guide values, and field-test and Guide values for individual cues were significantly correlated. These results were obtained in spite of the different data collection methods employed in the original detection study and in the field test.

Some difficulty might be expected in gaining acceptance of the Guide by police officers experienced in DWI enforcement. Many feel they have little or nothing to learn from the Guide, or that detection is not a primary problem in DWI enforcement. On the other hand, after using it, officers stated that the Guide would be of value for increasing patrol sensitivity to important DWI detection cues, training inexperienced patrol officers, writing DWI arrest reports, and providing court testimony in conjunction with DWI arrests. 
The Guide should be modified slightly, as shown in figure 6 . The DW! probability values in the modified Guide were based on data combined from the earlier detection study and the field test, providing a data base of 4662 detection events for these values. The following three cues were eliminated because they did not discriminate much beyond chance between OWI and DWS:

- Fast speed (more than $10 \mathrm{MPH}$ above limit)

- Failing to respond to traffic signals or signs

- Oriving with vehicle defect(s)

The modified Guide was further simplified by including only two instead of three adjustments: increasing values when two or more cues are observed, and estimating the probability of $B A C$ equal to or greater than .05. Eliminating the adjustment for three or more observed cues should further facilitate the understanding and use of the Guide, and enhance the accuracy of adjusted values. Also, DWI probability values are stated as "chances in 100" rather than "percentages of" to avoid potential confusion between probabilities and expected frequencies. Modifications in the Guide should be reflected in the booklet designed to accompany the Guide.

To support implementation of the Guide, short, color, sound, 16-mm motion picture was produced. The film should be used along with the booklet to introduce potential users to the Guide in a cost-effective manner. The film sumarizes how the Guide was developed, defines and illustrates the visual detection cues contained in the Guide, and describes how the cues should be employed for on-the-road detection of DWI. 


\section{DWI DETECTION GUIDE}

Chances in 100 of nighttime driver with BAC equal or greater than 107 TURNING WITH WIDE RADIUS . . . . . . . . . . . . 65 STRADDLING CENTER OR LANE MARKER . . . . . . 65 APPEARING TO BE DRUNK . . . . . . . . . . . . . . 60 ALMOST STRIKING OBJECT OR VEHICLE ............60 WEAVING . . . . . . . . . . . . . . . . . . . 60 DRIVING ON OTHER THAN DESIGNATED ROADWAY . . . . . 55

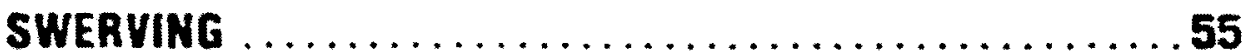
SLOW SPEED (MORE THAN 10 MPH BELOW LIMIT) .... . . 50 STOPPING (WITHOUT CAUSE) IN TRAFFIC LANE . . . . . . 50

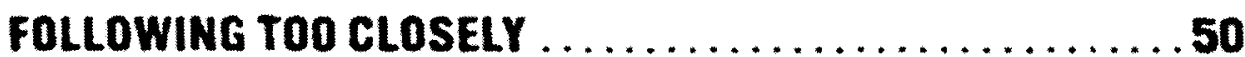
DRIFTING $\ldots \ldots \ldots \ldots \ldots \ldots \ldots \ldots \ldots \ldots \ldots \ldots \ldots \ldots \ldots \ldots$

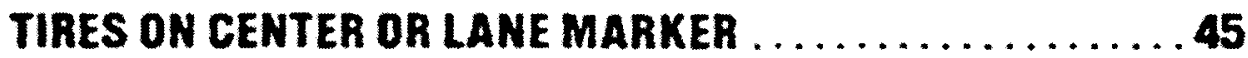

BRAKING ERRATICALLY . . . . . . . . . . . . . . 45 DRIVING INTO OPPOSING OR CROSSING TRAFFIC . . . . . . 45 SIGNALLING INCONSISTENT WITH DRIVING ACTIONS ... . 40 SLOW RESPONSE TO TRAFFIC SIGNALS ...........40 STOPPING INAPPROPRIATELY (OTHER THAN IN LANE) ... . 35 TURNING ABRUPTLY OR ILLEGALLY ............. 35 ACCELERATING DR DECELERATING RAPIDLY . . . . . . . 30 MEADLIGHTS OFF . ....................

Special adjustment to the cue values

- 2 or more cues observed: add 10 to the larger value

- BAC equal to or greater than .05: add 15 to the value obtained for BAC equal to or greater than .10

Figure 6. Modified Drunk Driver Detection Gulde. 


\section{APPENDIX}

The Drunk Driver Detection Guide is illustrated below in actual size, $8.73 \mathrm{~cm} \times 12.38 \mathrm{~cm}(3-7 / 16$ inches $\times 4-7 / 8$ inches $)$. The Guide was made of white plastic card stock. The printing was in dark blue.

A booklet, "Drunk Driver Detection: An Explanation of the Drunk Driver Detection Guide," was prepared to accompany each Guide. The book let was printed in blue on white paper, was stapled at the fold, and measured $10.16 \mathrm{~cm} \times 20.96 \mathrm{~cm}$ ( 4 inches $\times 8 \frac{1}{4}$ inches). It is shown on the following pages.

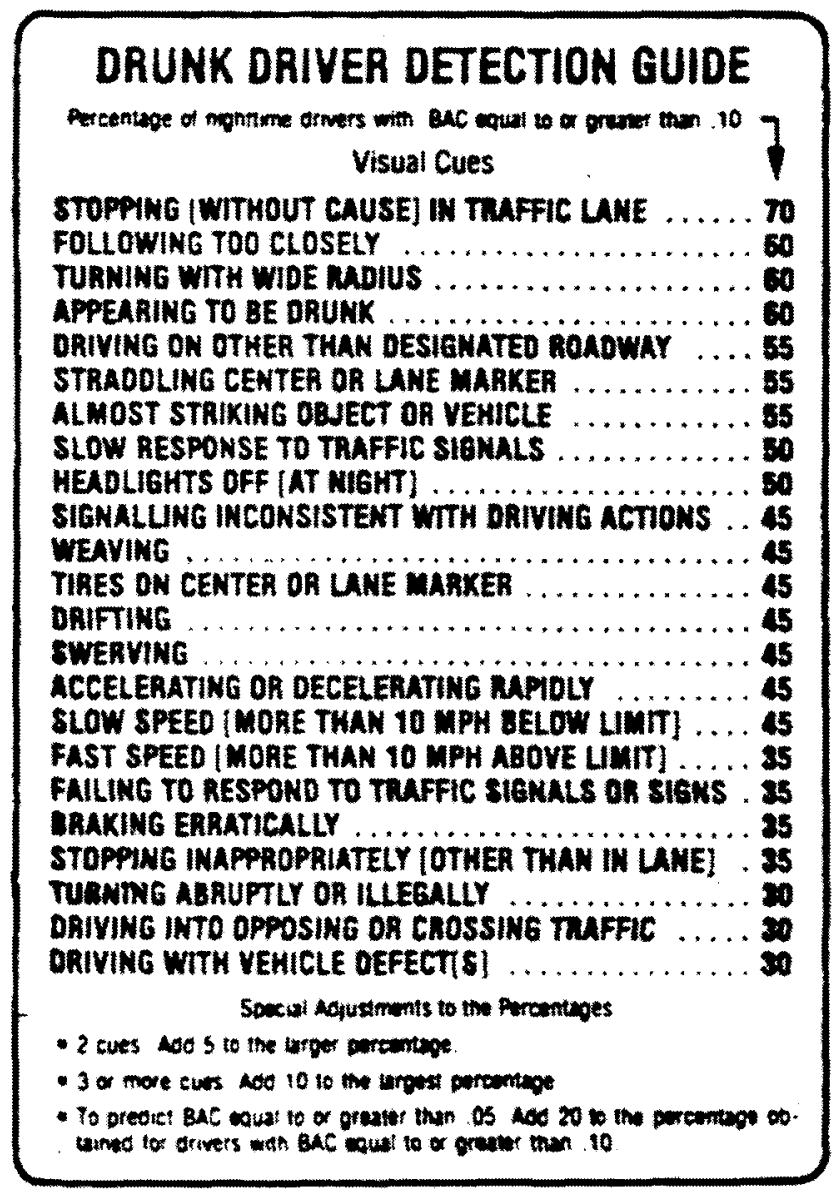




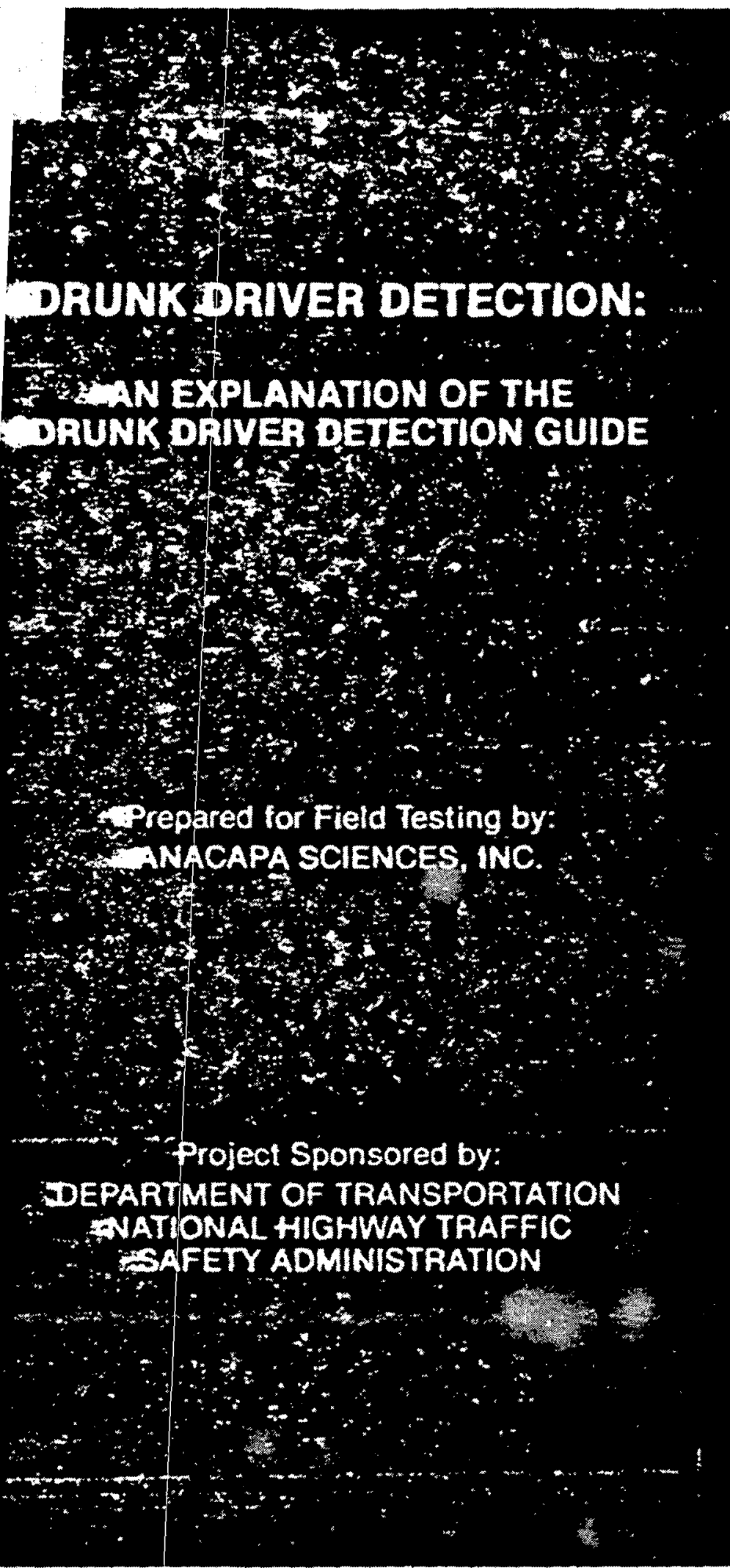

\section{INTRODUCTION}

This booklet provides a detailed explanation of the visual cues contained in the Drunk Driver Detection Guide. These cues for discriminating nighttime drunk drivers from nighttime sober drivers were extracted from interviews with a wide variety of law enforcement specialists in drunk driver detection, from detailed analysis of over one thousand drunk driver arrest reports from different geographical regions, and from a field study in which cues obsened in more than 600 patrol stops were correlated with driver $B A C$ levels. Thus, the 23-cue Drunk Driver Detection Guide is the most systematically developed method currently available for visually predicting whether a vehicle operated at night is being driven by a drunk driver or a sober driver.

This booklet contains:

- A reproduction of the Drunk Driver Detection Guide

- A short explanation about the percentages presented in the Guide

- Explanations of the 23 visual cues used in the Guide 


\section{PERCENTAGE INDICATORS}

The percentage given after each cue in the Guide indicates the proportion of drivers on the average who exhibit that particular cue and who also have a Blood Alcohol Concentration (BAC) equal to or greater than .10. For example, the 70 percent following the first cue, Stopping [Without Cause] In Traffic Lano, means that out of 100 nighttime drivers who stop without cause in the traffic lane, on the average 70 will have a BAC equal to or greater than .10 .

Each percentage shown in the Guide is based on the observation of one cue. However, since more than one cue is often observed for a driver, the following simple adjustments are used to obtain percentages for multiple cues:

- If two cues are observed, find the larger of the two cue percentage values and add 5 to it.

- If three or more cues are observed, find the largest cue percentage value and add 10 to it.

When you want to predict the proportion of drivers who have a BAC equal to or greater than .05 , add 20 to the percentage value that was obtained in predicting driver BAC equal to or greater than .10 . This applies to multiple cues as well as to single cues.

Using the percentage indicators to decide whether or not to stop a particular driver will be a matter of department policy and/or individual officer judgement. The Guide is only an aid that provides basic information concerning which visua! cues are most likely to indicate a nighttime drunk driver. 


\section{VISUAL CUE DEFINITIONS}

Stopping [Without Cause] in Traffic Lane (Percentage: 70 )

The critical element in this cue is that there is no observable justification for the vehicle to stop in the traffic lane; the stop is not caused by traffic conditions, traffic signals, an emergency situation, or related circumstances. Intoxicated drivers might stop in lane when their capability to interpret information and make decisions becomes severely impaired. As a consequence, stopping (without cause) in the traffic lane is likely to occur at intersections or other decision points.

Following Too Closely (Percentage: 60)

The vehicle is observed following another vehicle while not maintaining the legal minimum separation.

\section{Turning With Wide Radius}

(Percentage: 60)

During a turn, the radius defined by the distance between the turning vehicle and the center of the turn is greater than normal. This cue is illustrated below.

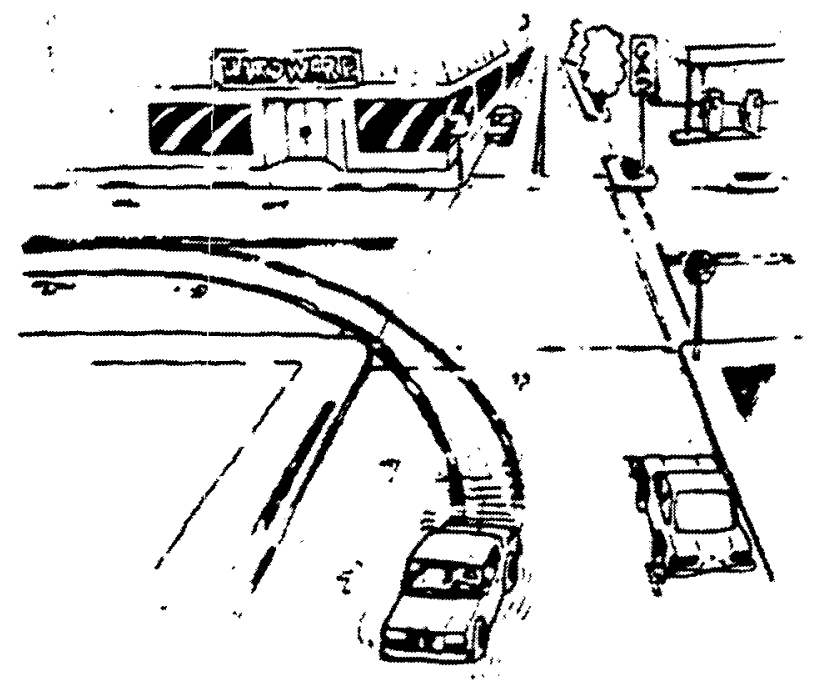

Appearing to be Drunk (Percentage: 60)

This cue is actually one or more of a set of indicators related to the personal behavior or appearance of the driver. Examples of specific indicators might include:

- Tightly gripping the steering wheel

- Face close to the windshield

- Eye fixation

- Slouching in the seat

- Gesturing erratically or obscenely

- Drinking in the vehicle

- Driver's head protruding from vehicle

The drawing below illustrates the first three indicators in the above list.

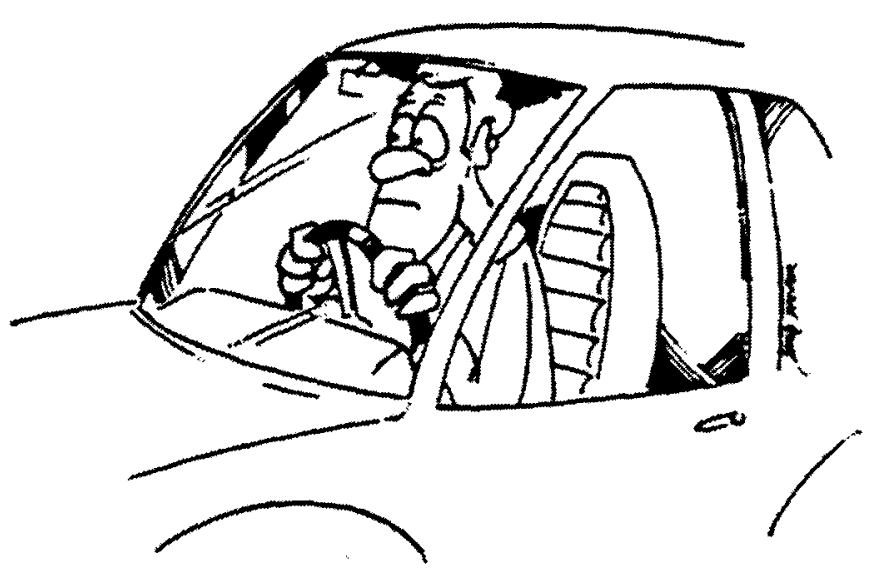

Driving on Other Than Designated Roadway (Percentage: 55 )

The vehicle is observed being driven on other than the roadway designated for traffic movement. Examples include driving: at the edge of the roadway, on the shoulder, off the roadway entirely, and straight through turn-only lanes or areas. The last example is illustrated on the next page. 
Driving on Other Than Designated Roadway

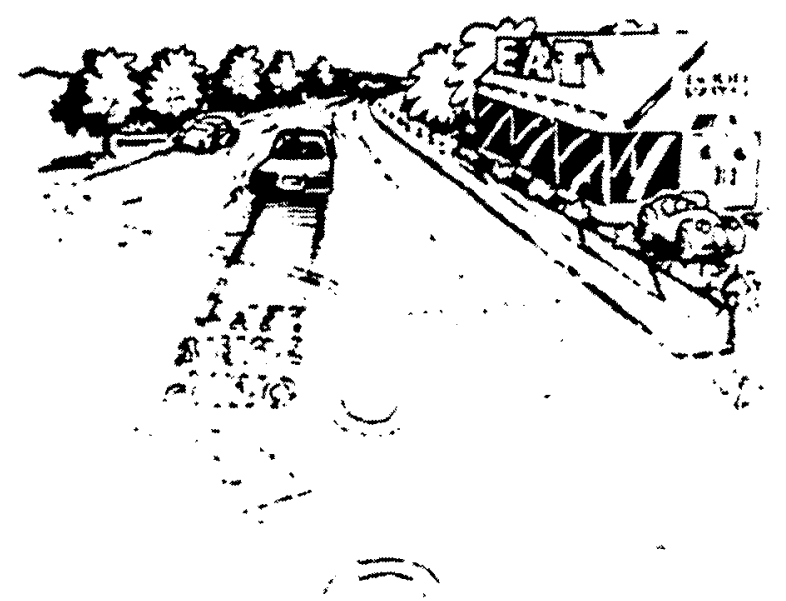

Straddling Conter or Lane Marker (Percentage: 55)

The vehicle is moving straight ahead with the center or lane marker between the left-hand and right-hand wheels.

\section{Almost Striking Object or Vohiclo (Percentage: 55)}

The observed vehicle almost strikes a stationary object or another moving vehicle. Examples include: passing abnormalIy close to a sign, wall, building, or other object; passing abnormally close to another moving vehicle; and causing another vehicle to maneuver to avoid collision.

\section{Slow Response to Trafflc Signals (Percentage: 50)}

The observed vehicle exhibits a longer than normal response to a change in traffic signal. For example, the driver remains stopped at the intersection for an abormally long period of time atter the traffic signal has turned green.

\section{Hoadlights Off [At Night]}

(Percentage: 50)

The observed vehicle is being driven with both headlights off during a period of the day when the use of headlights is required.

\section{Signalling Inconsistont With Driving Actions (Percentage: 45)}

A number of possibilities exist for the driver's signalling to be inconsistent with the associated driving actions. This cue occurs when inconsistencies such as the following are observed: failing to signal a turn or lane change, signalling opposite to the turn or lane change executed, signalling constantly with no accompanying driving action, and driving with four-way hazard flashers on. An example of this cue is illustrated below.

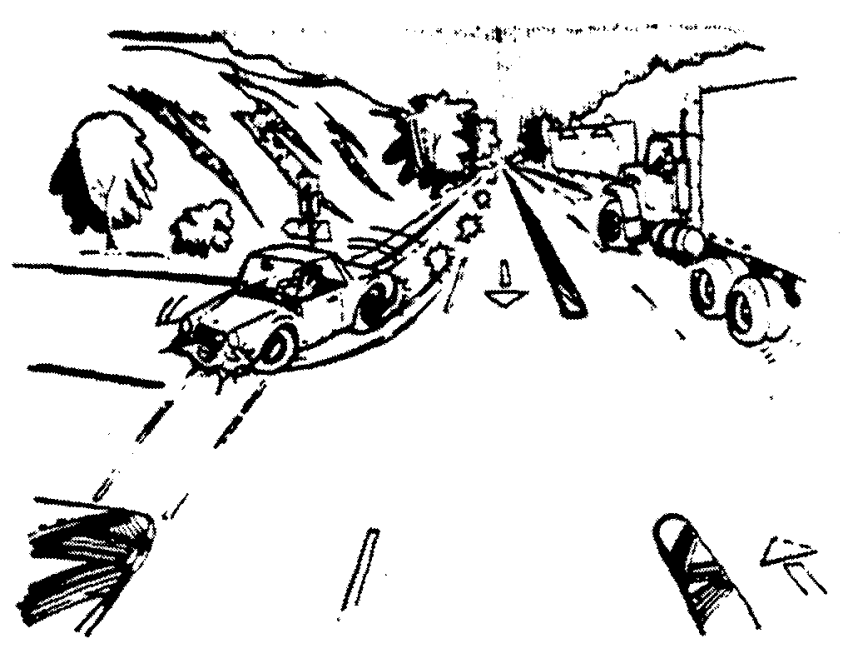

Weaving (Percentage: 45)

Weaving occurs when the vehicle alternately moves toward one side of the roadway and then the other, creating a zig-zag course. The pattern of lateral movement is relatively regular as one steering correction is closely followed by 
another. Weaving is Illustrated by the drawing below.

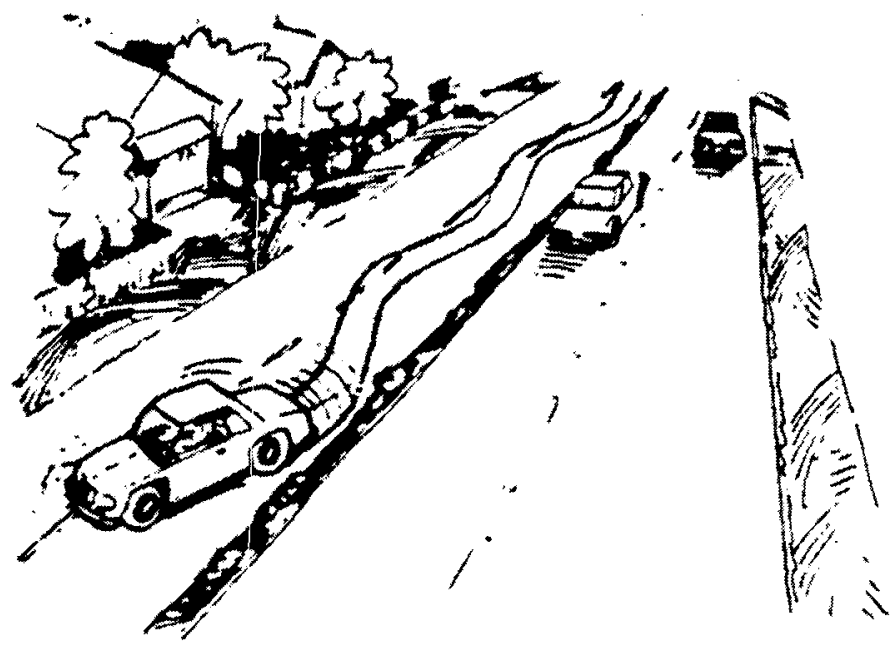

Tires on Center or Lane Marker

(Percentage: 45)

The left-hand set of tires of the observed vehicle is consistently on the center line, or either set of tires is consistently on the lane marker.

\section{Drifting (Percentage: 45 )}

Drifting is a straight-line movement of the vehicle at a slight angle to the roadway. As the driver approaches a marker or boundary (lane marker, center line, edge of the roadway), the direction of drift might change. As shown in the lllustration on the next page, the vehicle drifts across the lane marker into another lane, then the driver makes a correction and the vehicle drifts back across the lane marker. Drifting might be observed within a single lane, across lanes, across the center line, onto the shoulder, and from lane to lane.

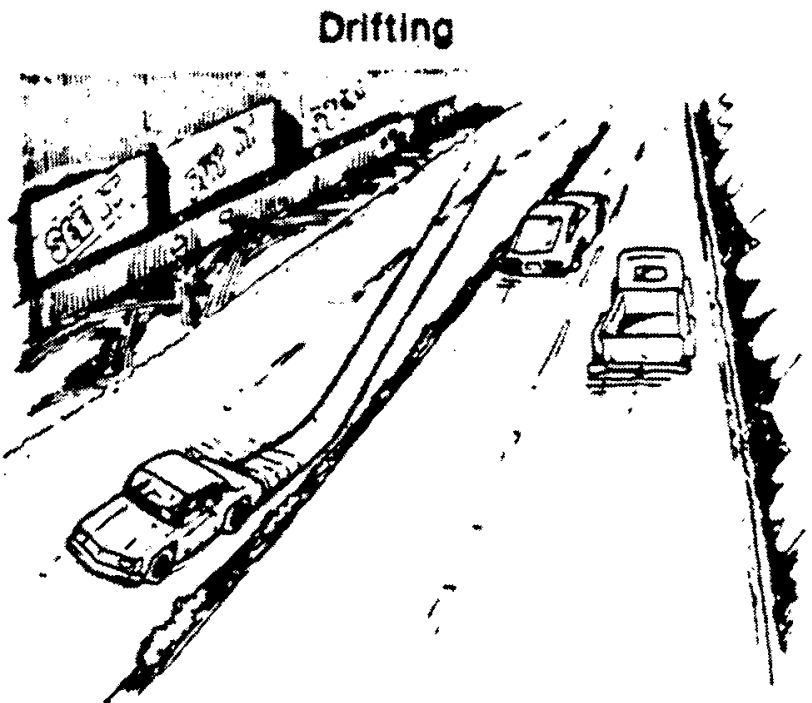

Sworving (Percentage: 45)

A swerve is an abrupt turn away from a generally straight course. Swerving might occur directly after a period of driftIng when the driver discovers the approach of traffic in an oncoming lane or discovers that the vehicle is going off the road; swerving might also occur as an abrupt turn is executed to return the vehicle to the traffic lane. In the illustration below, a swerve was executed to return to a lane after a period of drifting toward opposing traffic.
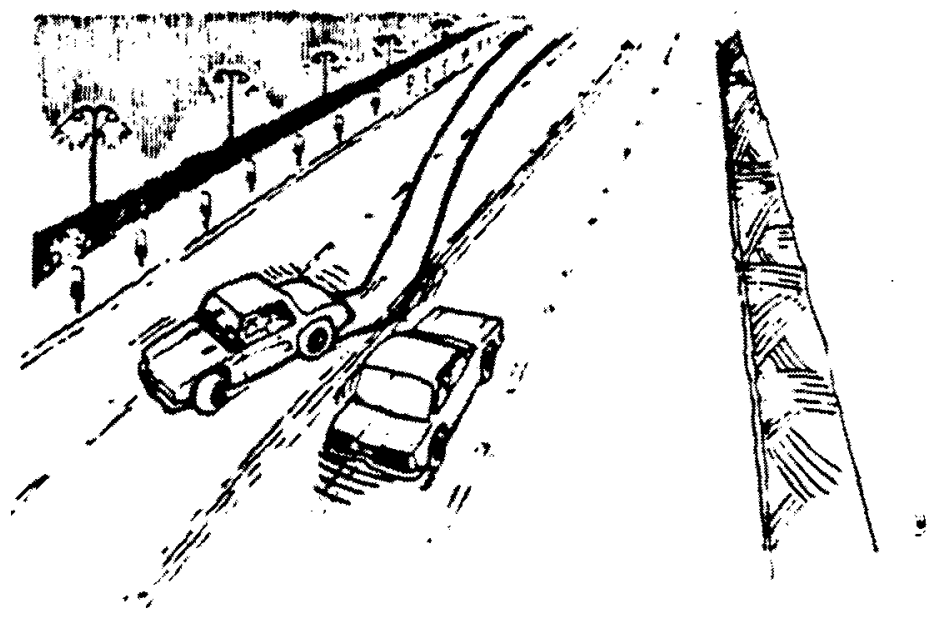
Accelerating or Decelerating Rapidiy (Percentage: 45)

This cue encompasses any acceleration or deceleration that is significantly more rapid than that required by the traffic conditions. Rapid acceleration might be accompanied by breaking traction; rapid deceleration might be accompanied by an abrupt stop. Also a vehicle might alternately accelerate and decelerate rapidly.

\section{Slow Speed [More than 10 MPH Below} Limit] (Percentage: 45)

The observed vehicle is being driven at a speed that is more than $10 \mathrm{MPH}$ below the speed limit.

\section{Fast Speed (More than 10 MPH Above Limit] (Percentage: 35)}

The observed vehicle is being driven at a speed that is more than $10 \mathrm{MPH}$ above the speed limit.

\section{Failing to Respond to Traffic Signals or Signs (Percentage: 35 )}

The observed vehicle fails to respond to a traffic signal or sign. For example, the vehicle fails to stop for a red traffic signal, fails to stop for a stop sign, or fails to slow for caution signals.

Braking Erratically (Percentage: 35 )

The driver of the observed vehicle is braking unnecessarily frequently, maintaining pressure on the brake pedal ("riding the brakes"), or braking in an uneven or jerky manner.

Stopping Inappropriately (Other Than in Traffic Lano] (Percentage: 35 )

The observed vehicle stops at an inappropriate location or under inappropriate conditions, other than in the traffic lane: Examples include stopping: in a prohibited zone, at a crosswalk, far short of an intersection, on a walkway, across lanes, for a green traffic signal, or for a flashing yellow traffic signal. The drawing below shows one example of this cue.

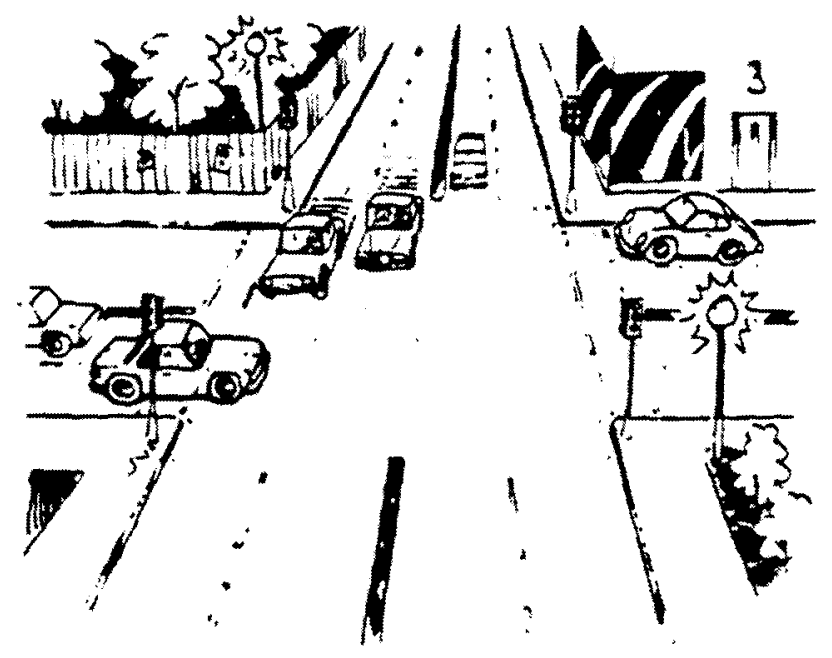

Turning Abruptly or Illegally

(Percentage: 30 )

The driver executes any turn that is abnormally abrupt or illegal. Specific examples include turning: with excessive speed, sharply from the wrong lane, a $U$ illegally, and outside the designated turn lane. This cue is illustrated below.

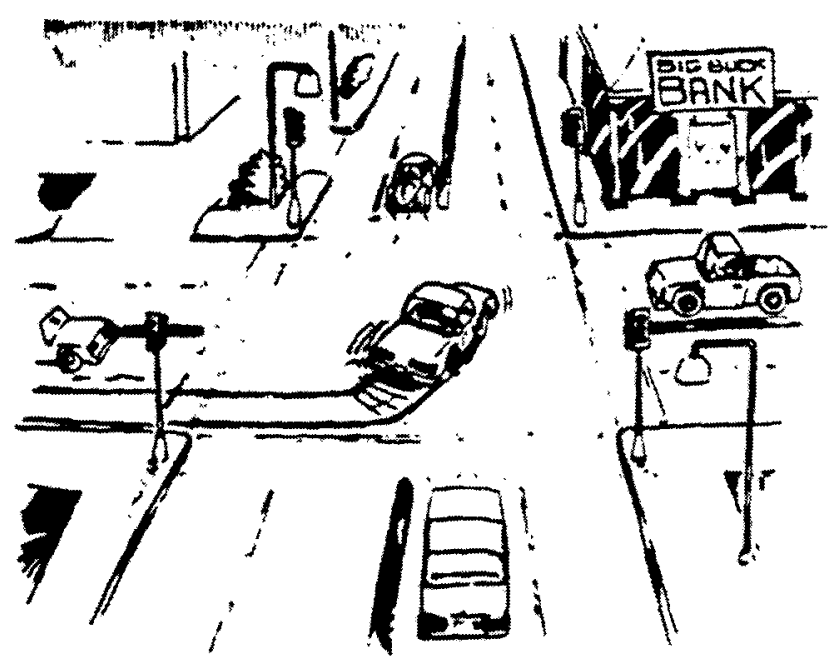


Driving Into Opposing or Cmasing Trattic (Percentage: 30)

The vehicle is observed heading into opposing or crossing traffic under one or more of the following circumstances: driving in the opposing lane, driving the wrong way on a one-way street, backing into traffic, failing to yield the right-ofway. The last circumstance is illustrated below.

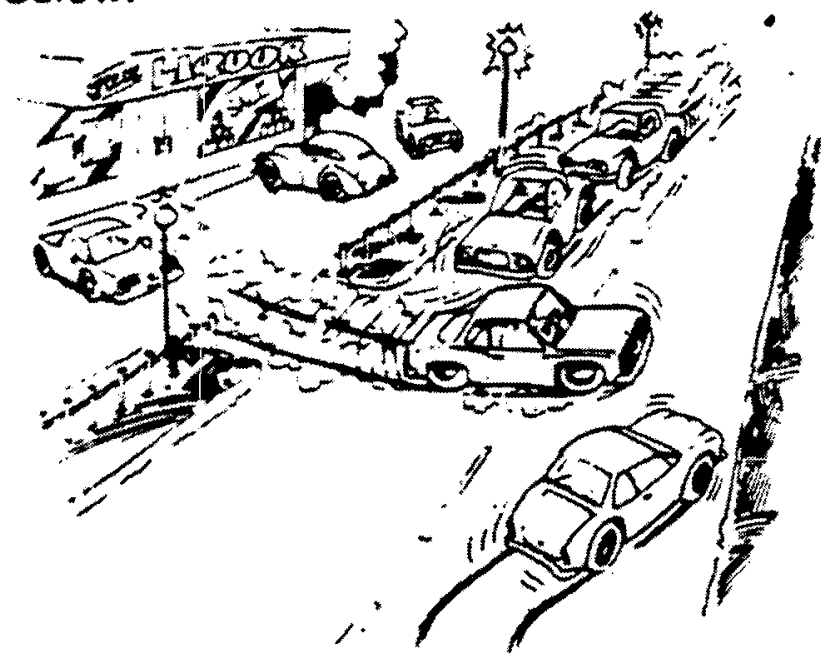

Driving with Vohicle Dofect[s]

(Percentage: 30)

The observed vehicle is being driven with one or more defects, such as: faulty headlight, faulty taillight, flat tire, or one of many other observable mechanical or electrical defects. 